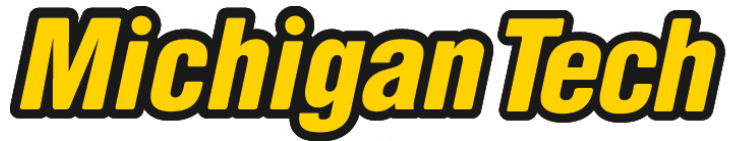 \\ Michigan Technological University Create the Future Digital Commons @ Michigan Tech
}

\section{STUDENTS' RHETORICAL STRATEGIES IN TRANSLINGUAL ENCOUNTERS ON CAMPUS}

Laura Moeller

Michigan Technological University

Follow this and additional works at: https://digitalcommons.mtu.edu/etds

Part of the Communication Commons, Education Commons, and the Rhetoric Commons Copyright 2014 Laura Moeller

\section{Recommended Citation}

Moeller, Laura, "STUDENTS' RHETORICAL STRATEGIES IN TRANSLINGUAL ENCOUNTERS ON CAMPUS", Master's Thesis, Michigan Technological University, 2014.

https://doi.org/10.37099/mtu.dc.etds/891

Follow this and additional works at: https://digitalcommons.mtu.edu/etds

Part of the Communication Commons, Education Commons, and the Rhetoric Commons 


\title{
STUDENTS' RHETORICAL STRATEGIES IN TRANSLINGUAL ENCOUNTERS ON CAMPUS
}

\author{
By \\ Laura Moeller
}

\section{A THESIS}

Submitted in partial fulfillment of the requirements for the degree of MASTER OF SCIENCE

In Rhetoric and Technical Communication

MICHIGAN TECHNOLOGICAL UNIVERSITY

2014

(C) 2014 Laura Moeller 
This thesis has been approved in partial fulfillment of the requirements for the Degree of MASTER OF SCIENCE in Rhetoric and Technical Communication.

Department of Humanities

Thesis Advisor: Dr. Lauren M. Bowen

Committee Member: Dr. Beatrice Smith

Committee Member: Dr. Abraham Romney

Committee Member: Dr. Mari Buche

Department Chair: $\quad$ Dr. Ronald Strickland 


\section{Table of Contents}

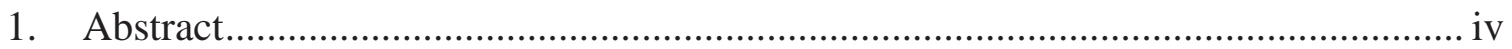

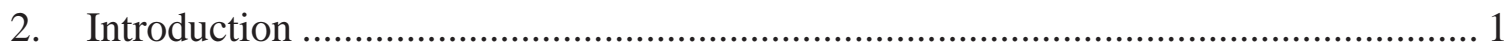

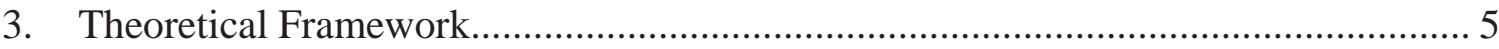

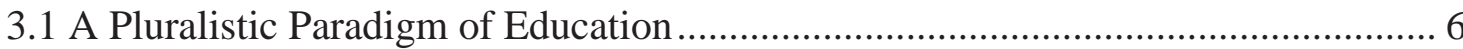

3.3 The Classroom as Kairotic Space..................................................................... 16

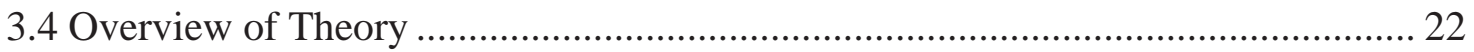

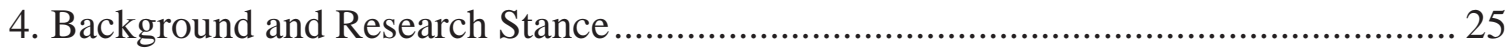

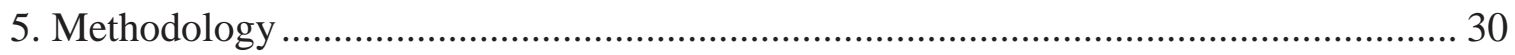

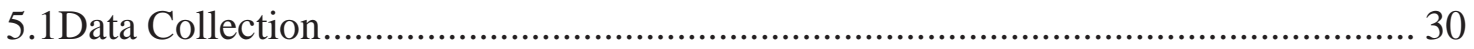

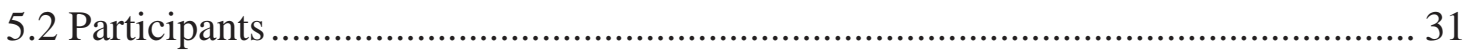

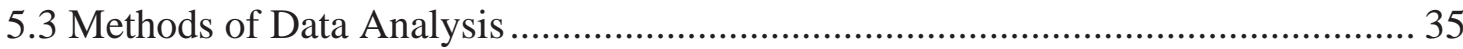

5.4 "Strategies" as Rhetorical Practices in Kairotic Spaces............................................ 38

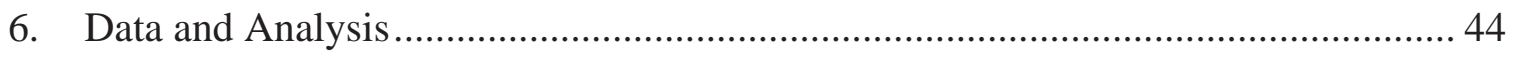

6.1 Key Questions and Arguments.......................................................................... 47

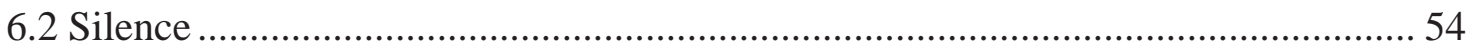

6.3 Establishing Academic Credibility ..................................................................... 59

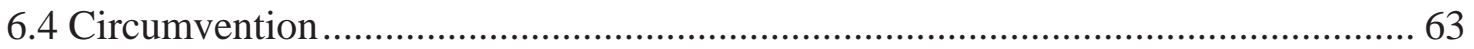

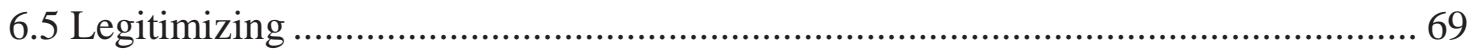

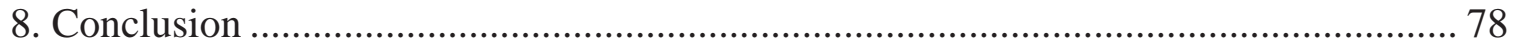

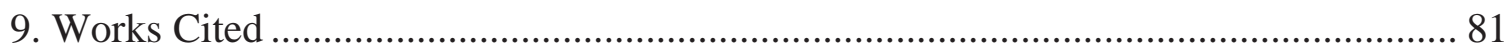




\section{Abstract}

This thesis examines the ways in which linguistic minority students assert themselves as rhetorical agents when faced with the expectation of impromptu verbal responses. Based on a study that aims at identifying specific rhetorical strategies these students employ, the goal of this thesis is to theorize ways in which linguistic minorities deal with the challenges of fast-paced, high-stakes interactions. The practices that emerge from data analysis suggest that such strategies tend to be reactive rather than proactive and highly dependent on context. While they are valuable ways for linguistic minorities to navigate their ways in specific moments, the thesis argues that they are ultimately insufficient to create a sense of agency and empowerment. Future research hence needs to address ways in which strategies can be consciously trained and employed in order to create a more inclusive classroom experience for linguistic minority students. 


\section{Introduction}

Last semester, within the framework of a class on community literacies, I conducted a research project that aimed at identifying challenges linguistic minorities face in the composition classroom. I interviewed three non-native speakers of English on their experiences with interpersonal exchanges during group work sessions. The following quotation by a male Chinese student has been on my mind ever since:

"There was one situation that was really kind of awkward. There was this Indian girl who said something and the two other guys [two white American males] don't understand the point she's trying to make. So they're just like - uhm, this takes too long. Let's just skip it. So, it's a little bit sad."

Yi's experience points to the issue of timing in interpersonal exchanges. The requirement of impromptu responses is characteristic of classroom interaction: during phases of group work, peer review, or class discussion. Margaret Price employs the notion of kairotic spaces to theorize situations such as the one described by Yi: in kairotic spaces, interaction is characterized by in-person contact, time constraints, high stakes and asymmetrical power relations. The use of the term "kairotic" points to the rhetorical nature of such exchanges: agents in kairotic spaces communicate across various modes to negotiate meaning and navigate their ways through these highly complex encounters.

Yi's story reveals that the stakes in these interactions may differ from one student to another: communicating across (perceived) language boundaries poses an additional challenge especially for students who constitute, or are perceived as, a linguistic minority. How do linguistic minorities navigate kairotic spaces in the classroom, spaces in which direct interaction is shaped by unequal power relations and high stakes? What 
strategies do they draw on to prevail against experiences of silencing? Do these strategies suffice, in that they ensure their voices are being heard, or are they strategies that tend to be reactive, a response to exclusion and discrimination, that may serve them in the moment but do not help students assert themselves as agents in the long run? If that is the case, what can we, as teachers and researchers, do in order to empower linguistic minorities? What frameworks exist in scholarship that we can draw on? And finally, how do students that speak a standard variety of English experience interactions with multilingual students? How do they experience these encounters in kairotic spaces? How can we help them engage in cross-boundary discourse?

This thesis aims at providing answers to some of these questions. At its core is a qualitative research project which I conducted in two first-year composition classroom at Michigan Technological University. I observed the classroom for four weeks, focusing on interactions that linguistic minorities - both students and instructors- engaged in. By "linguistic minorities," I mean students and instructors who self-identified as multilingual and as speakers of an English variety that deviated from the locally dominant variety. I would like to emphasize that I am not employing the term "minority" to victimize the group I observed or reinforce a notion of language which posits clear cuts and boundaries between varieties. I am referring to multilingual students as minorities because it reflects how they experience the classroom, and how they are perceived by those who constitute a majority.

My aim during research was to identify moments in which participants faced challenges in kairotic interactions and examine how they assert agency in these situations. Three students and both instructors identified as multilingual; I interviewed all 
five of them in open-ended interviews to complement my observation, and thus collected their narratives of classroom experience. I also interviewed students who identified as monolingual to learn about their experiences and perspectives, but my focus in this thesis is on those students who experience being linguistic minorities in the kairotic spaces of an American university. While I have no intention of victimizing multilingual students, I do believe that, in these spaces, they face additional struggles that speakers of dominant varieties of American English do not face. Secondly, I believe that scholars and teachers in the field of rhetoric can benefit from better understanding those students whose background they may not share. What is of particular interest is the perspective of the instructors, both of whom are Ghanaian women teaching in a predominantly white environment: having transitioned from being part of a majority in black Africa to being a minority in Midwestern America, their experiences are unique and their identities highly complex. As instructors, they are in a powerful position in the kairotic space of the classroom; yet as black, multilingual women in a nearly all-white classroom, how do they negotiate their identities and navigate kairotic interactions?

With regards to the data, my primary aim was to identify ways in which multilingual students and instructors, who constitute a minority in their respective classrooms, navigate kairotic spaces rhetorically. The study is qualitative, thus I see my results as exemplary rather than universal; nevertheless, these examples point to more universal, broader issues in the field: they may yield questions regarding our practices of teaching and researching, our paradigms of pedagogy, and the ways in which we conceive of language. Clearly, Michigan Tech is only one example of a university that, while located in an environment that is ethnically, racially and linguistically quite 
homogenous, has a diverse body of students from all across the world. Tendencies to recruit international students can be observed across America, even worldwide. Scholars in rhetoric, composition, education and literacy studies have long asked themselves how we can create a classroom experience that is more inclusive for all of our students. With this project, I hope to make a small, exemplary, yet meaningful contribution to this discourse. 


\section{Theoretical Framework}

In Taking it Personally: Racism in the Classroom from Kindergarten to College,

Ann Berlak and Sekani Moyenda (2001) address issues of racism in American classrooms. Their piece is centered around a graduate class session on diversity, in which Moyenda, an African American woman, confronts predominantly white middle class future teachers with the realities of (their own) racism. Only one African American student is present in their graduate class; in his journal, the student writes "I know you [the instructor] would like me to speak more when we have open discussions, but I don't believe our classmates can even hear ME... I feel totally shut out sometimes in our class..." (Berlak \& Moyenda, p. 81).

The student's statement summarizes the exclusion that minority students regularly experience in the classroom. His experience is one of silence and being silenced. He chooses not to participate in discussions, knowing he, as an African American male in a predominantly white classroom, will not be heard. What lies at the core of this student's outcry is what bell hooks (1994) calls "the issue of voice", when she asks, "Who speaks? Who listens? And why?" (p. 41). Scholars in and outside of rhetoric and composition have complicated the notion of a supposedly neutral educational setting, emphasizing, as Jacqueline Jones Royster (2011) puts it, the "pressing need to construct paradigms that permit us to engage in better practices in cross-boundary discourse, whether we are teaching, researching, writing, or talking with Others, whoever those Others happen to be" (p. 564).

What must these paradigms in cross-boundary discourse look like? How should we conceive of education in a manner that allows for better practices when we are 
engaging with Others? How do we need to conceptualize language in such a way that it is inclusive of all the voices as they are shaped by students' identities? And how should we conceive of the classroom in a manner that acknowledges the "asymmetrical relations of power" that are at play in a particular classroom (Pratt, 1991, p. 34)? In the following section, I will address these questions, drawing on approaches scholars in rhetoric, composition, literacy studies and sociolinguistics have taken, to offer a theoretical framework that suits the purpose of examining interactions in heterogeneous groups of students, or, in Jones Royster's word, a paradigm for "researching [...] Others."

\subsection{A Pluralistic Paradigm of Education}

Since the research I am conducting is concerned with speakers of multiple languages in an educational setting, I will start out by drawing on scholarship that addresses the intersections of language and pedagogy. The Multiliteracies reader published by the New London Group in 2000 has significantly shaped my understanding of language and literacy pedagogy, as it pushes for a pluralistic approach to education. It may thus serve here as a starting point to establish a theoretical framework for engaging with "others" in educational settings. More specifically, it may help formulate goals of pedagogy that address issues speakers of multiple languages face in the classroom.

In 1994, a group of scholars from a wide range of disciplines including composition, rhetoric, literacy studies, English studies and linguistics met in New London, New Hampshire, to discuss the ways in which literacy teaching can address rapid changes in an increasingly globalized world. As the "New London Group," they launched the Multiliteracies Project and collectively contributed to the publication of Multiliteracies: Literacy Learning and the Design of Social Futures (Cope \& Kalantzis 
2000), to frame a literacy pedagogy that breaks down barriers to educational success arising out of differences in student identities. They coin the term multiliteracies, which encompasses two "arguments we might have with the emerging cultural, institutional, and global order" (Cope \& Kalantzis, 2000, p. 5).

Their first argument relates to the "increasing multiplicity and integration of significant modes of meaning-making" (Cope \& Kalantzis, p. 5). It poses a challenge to the dominant conception of written language as a superior mode of communication; it highlights the multimodality of communication and meaning making, expanding the notion of "text" to the visual, aural, spatial and behavioral mode (Cope \& Kalantzis, p. 5). In particular, the New London Group emphasizes the emergence of the internet as well as interactive media - which has vastly expanded since the 1990s, especially with the arrival of social networking and smartphones - as opening up new possibilities of communication. With technology expanding so rapidly, they argue, "there cannot be one set of standards or skill that constitutes the ends of literacy learning" (Cope \& Kalantzis , p.6).

Their second argument addresses processes of globalization and local diversification. On the one hand, English is becoming both a world language and "a common language of global commerce, media and politics" (Cope \& Kalantzis, p. 6). At the same time, the English language is in a constant process of diversification. These new Englishes arise, characterized by "accent, national origin, subcultural style and professional or technical communities" (Cope \& Kalantzis, p. 6). This cultural and linguistic diversification poses a challenge to the ways in which we traditionally conceive of language pedagogy and learning. Formal instruction, standard varieties and the 
concept of national language no longer correspond to the realities of a world characterized by cross-cultural contact and ever-increasing diversity.

Cope and Kalantzis identify the multitude of life experience and backgrounds students bring with them as one of the core dilemmas of (literacy) education. Education promises improvement for everyone, but it is a promise our educational system can hardly keep: "you get a better education if you are wealthier; if you speak the national language; if you belong to the most powerful ethnic group; if you live in the right neighborhood or country; or if you are male" (p. 122). Education, they argue, cannot realistically promise equality, in the sense that everyone has equal opportunity to access to wealth and social or political influence Yet what lies underneath the promise of equality is the promise of equity: "that the game of opportunity is fair and that its rules are even-handed" (Cope \& Kalantzis, p. 122). Equity, they argue, is realistically speaking the best that our educational system can promise. This promise implies that for students who are systemically disadvantaged, education at least provides a chance:

However, not every system of education is inherently suited to fulfill this promise. Cope and Kalantzis distinguish between four basic forms of modern education: exclusion, assimilation, multiculturalism and pluralism. While exclusion can take a variety of forms, it comes down to particular groups not being able to "get in" to the system of education (Cope \& Kalantzis, p. 123). Assimilation implies that success in education is possible for groups and individuals who are not part of the dominant group, provided they adapt and "cross over" to the mainstream. Multiculturalism is a powerful and popular concept of superficially recognizing diversity. However, the distinction between 'us' and 'them' remains: "different lifeworlds might be made an object of study or celebrated as folkloric 
color, but only insofar as the fundamental framework of seeing, valuing and knowing remains singular and undisturbed" (Cope \& Kalantzis, p. 124). Thus, all three forms are ultimately varieties of exclusion.

Cope and Kalantzis advocate a pluralistic form of education as one that can fulfill the promise of equity: in a pluralistic system, "the mainstream [...] is itself transformed" (p. 124). Rather than conceiving of culture as monolithic and stable, pluralism embraces "openness, negotiation, experimentation, and the interrelation of alternative frameworks and mindsets" (Cope \& Kalantzis, p. 124). To call for pluralism is to call for a fundamental paradigmatic shift in education.

Exclusion in educational settings affects students in different ways and functions on various levels: Cope and Kalantzis imply that those who experience exclusion may "differ" with regard to identity markers such as economic status, social status, language, and ethnicity (p.122). I would add that several other markers - ability status, sexual orientation, gender identity or age, to name only a few - may be added to the list. While in the context of this thesis, I will focus mainly on language minorities, it is crucial to keep in mind the intersections of various identity markers. Students enter the classroom with complex histories, backgrounds and identities, and they may prioritize different aspects of their identities in different contexts.

Multiliteracies may have been published almost fifteen years ago, but I would suggest that 1) the New London Group's critique of exclusion in educational settings continues to hold true, and 2), that their call for a pluralistic paradigm of education is still relevant. Some of the scholarship I will address later provides examples of ways in which this is the case. I hope that by researching cross-lingual interaction I can contribute to the 
discourse of educational pluralism, as a form of education that regards diversity - in every respect - as the 'norm'.

\subsection{Mono-, Multi-, or Translingual? A Paradigm of Global English}

Since, as I previously pointed out, my main concern in this particular project is to examine linguistic minorities, an aspect that needs to be theoretically embedded is the specific role of language in the overall discourse of globalization and diversification: In

what ways does our understanding of language contribute to the aforementioned forms of exclusion? How can we conceive of language in such a manner that it is in accordance with a more pluralistic paradigm? In order to address these issues, I will now consider scholarship that more specifically addresses language as one particular aspect of pluralism. In Multiliteracies, primarily the contribution of Joseph Lo Bianco is of interest here.

Lo Bianco (2000) argues that as a result of globalization, cultural tensions arise out of "intra-lingual diversification", which results in policies that aim at establishing a monolingual standard (p. 93). At the same time, "inter-language" tensions collapse the idea of the "national standard language" as a unifying element of national identity (Lo Bianco, p. 93). However, language diversity, Lo Bianco highlights, has existed in the past; he traces the idea of a single national language as a distinctive element of a group's identity back to romantic philosophy. Within this cultural movement, which accompanied the formation of nation states, monolingualism became the norm (Lo Bianco, p. 96). A pedagogy that takes into account the global changes of the late twentieth and twenty first century, Lo Bianco argues, “cannot but be multilingual” (p. 105). 
While Lo Bianco's work provides an overview of the issue, more recent scholarship has dedicated a significant amount of work to language diversification. For this reason I will trace the discourse revolving around what Lo Bianco calls "multilingualism" and discuss the various approaches taken. Some of the works cited here are taken from scholars focused on sociolinguistics, yet their discussion of "multilingualism", as I will show in the following, ties in well with issues of literacy studies, rhetoric and composition.

Monolingualism, as Bruce Horner and John Trimbur argued in 2002, is treated as the "norm" in composition classrooms (and elsewhere, I would add), even if it does not correspond to students' translingual realities. Hence, institutions and individuals employ terms such as "international", "foreign" and "other", which is highly problematic, as they always imply a deviation from an imagined norm (Horner et al., 2002, p. 617-618). Paul Kei Matsuda (2006) emphasizes that the "myth of linguistic homogeneity" ascribes privilege to certain varieties - a myth common among instructors and scholars, who thus "alienate" students deviating from what is perceived as the norm (p. 639). He critiques institutions that recruit international students merely to "increase visible diversity and enhance their reputation", and then leave behind those who do not fit into the "monolingual mainstream" (Matsuda, p. 640). Horner and Trimbur (2002) thus argue in favor of an "internationalist perspective" on written English, while emphasizing they are not challenging the fact that instruction takes place in English (p. 624). This shift in perspective would take into account the relation English bears to other languages and impact of increasing global connectedness. 
In a 2011 article, Horner, NeCamp and Donahue (2011) applaud that by then, a shift in composition studies to challenge the monolingual norm has emerged (p. 271). However, in order to push this development even further, composition scholars must take the multilingualist perspective beyond the classroom and employ it in their research (Horner et al., p. 272). They reject the "traditional" approach to multilingualism in which “discrete groups" speak different languages and are linguistically and spatially separated from one another: they reject the additive model of languages according to which a multilingual individual is the sum of multiple monolinguals. Rather, they argue that it is "someone with a unique and shifting blend of practical knowledge and use of multiple languages" (Horner et al., p. 286). What they call "translingual multilingulism" redefines English as a "heterogeneous, bustling, complicated, shifting, fluid mix of languages, dialects and creoles" (Horner et al., p. 288).

Horner et al. do not provide a discussion of what they mean by "translingual multilingualism", which is problematic considering especially that the term seems to imply the existence of multilingualisms that are not translingual. The perspective they propose, however, has been discussed extensively by Suresh Canagarajah, who details distinctions between different approaches to diverse global Englishes. His 2013 publication provides a more recent perspective on issues of language diversification and globalization. Particularly his theoretical chapter is rich in detail in its discussion of terminology; hence, it may help disentangle the multitude of terms I have come across in the works discussed so far (such as "multilingualism", "translingual multilingualism", "lingua franca" and "lingua mundi"). 
Canagarajah (2013), too, rejects what he calls the monolingual orientation, which, he argues, is based on a set of common assumptions on what efficient and successful communication should look like: practices of mixing languages in writing "violate our assumptions that a text should be constructed in only one language at a time and that its meaning should be transparent $[\ldots]$ We $[\ldots]$ believe that languages have their own unique systems and should be kept free of mixing with other languages for meaningful communication" (p. 1). This monolingual perspective ignores the ways in which hybrid forms of speech and writing may function as "creative strategies" people use to communicate and express their voices (Canagarajah p. 2). While hybrid forms of communication are not "new", recent forms of globalization, translingual contact, migration and technological developments have opened up new fascinating ways of interacting cross-lingually.

Exploring the history of English as a contact language, Canagarajah argues in favor of a paradigm shift towards understanding English as a language that has always been manifold. Efforts to acknowledge diverse Englishes have been made in the past, the "World Englishes" model being among the oldest ones. This model, in its original formulation, distinguishes between "norm providing", "norm developing" and "norm dependent" varieties of English. In spite of the fact that in the 1980s, the model provided radically new insight into the diversity of English and raised the general acceptance of emerging varieties, it “doesn't go far enough in pluralizing English or reflecting the dynamic changes in communicative practices" (Canagarajah p. 58). Scholars following this model focus on distinguishing new Englishes rather than treat them as emerging constantly; they furthermore continue to hold the assumption of a monolithic inner circle 
norm and leave out intersections between norm providing, developing and dependent varieties.

Canagarajah identifies a second model which he refers to as "English as an International Language” (p. 61). This model takes a somewhat less hierarchical approach; nevertheless, it upholds the enumerative approach of "counting" varieties and is norm based in that it identifies varieties by comparing them to "grammatical norms" (Canagarajah p. 62). He furthermore critiques that scholars following this model advocate the necessity of a norm to make cross-boundary communication possible

"English as a Lingua Franca" is an approach that holds on to the notion of a linguistic norm, but it does not view it as monolithic and neutral. The model values the creative ways in which multilingual speakers contribute to its emergence Scholars working with this model have thus shifted from an approach of language-as-function towards a conception of language-as-practice, but still give the impression "that there is another variety called English as a lingua franca" (Canagarajah, p. 65). Canagarajah, however, favors an approach that treats practices as primary and "grammatical norms as emergent" (p. 68). He argues that he conceives of lingua franca English (a term which he adopts to distinguish his scholarship from those focusing on English as a lingua franca) as a practice rather than as a permanent, solid version of English. The translingual approach highlights the importance of treating norms as fluid and always subject to change (Canagarajah, p.70). He thus proposes a paradigm that sees "various situational norms and labels" as evolving "from translingual English practices" (Canagarajah, p. 70).

The umbrella term of "translingual practice" is characterized by two claims: that "communication transcends individual languages" and that "communication transcends 
words and involves diverse semiotic resources and ecological affordances" (Canagarajah, p. 6). The first concept implies an understanding of languages as always in contact, influencing and complementing each other. Language users do not have separate labels or competences to draw on their language repertoire; grammatical norms and patterns are emergent and open to renegotiation; meaning does not arise from a stable grammatical system but from communicative practices of renegotiation. The second claim implies that communication is not limited to words, but draws on a variety of semiotic resources such as signs, symbols etc. - that work together to shape meaning. Communication is contextual in that "diverse modalities" function together, in social and physical environment (Canagarajah, p. 7). Thus, even for analytical purposes in linguistics, language must be treated as contextual, situational, and multimodal.

Canagarajah notes that he favors the term translingual over "multilingual", as the latter tends to treat languages in an additive manner. It is thus still rooted in the monolingual paradigm, whereas the translingual approach emphasizes the dynamic nature of language relationships (p.8). In this respect, his approach deviates from the approach Lo Bianco takes in his Multiliteracies piece. Its focus on language-as-practice also takes into account the intersections of what Lo Bianco calls "intra-language" and "interlanguage" diversification, in that Canagarajah, instead of assuming a stable norm, highlights the fluidity of boundaries and conceptualizes grammatical forms as emergent rather than fixed. Both acknowledge that historically, English has always been a contact language and needs to be treated at such; both Canagarajah and the New London Group also acknowledge the need to understand language as transcending the verbal. Most importantly, Canagarajah's work in sociolinguistics ties in with Cope and Kalantzis call 
for a pluralistic paradigm in education. Cope and Kalantzis argue for the need of a shift towards a pluralistic pedagogy in which the "mainstream" itself is transformed. Canagarajah suggests a paradigm of language based on the idea that (grammatical) language norms arise out of practice, thus proposing a perspective that challenges the notion of "mainstream" and "norm" altogether. Hence, Canagarajah's piece, while not explicitly centered around issues of pedagogy, can serve to inform the pedagogical approach outlined by the New London Group.

\subsection{The Classroom as Kairotic Space}

Considering the persisting myth of monolingualism and the ongoing dominance of a model of English as a uniform, monolithic, homogenous entity, the American college classroom becomes a crucible for language politics. The majority of the scholars referenced in the previous section refer to the space in which intercultural interaction takes place as a "contact zone" (Cope \& Kalantzis 2000; Canagarajah 2013). The term was coined by Mary Louise Pratt (1991), who defines "contact zones" as "social spaces where cultures meet, clash, and grapple with each other, often in contexts of highly asymmetrical relations of power, such as colonialism, slavery, or their aftermaths as they are lived out in many parts of the world today" (p. 34). She argues against the notion of languages as "speech communities", which are often theorized as "discrete, self-defined, coherent entities, held together by a homogeneous competence or grammar shared identically and equally among all the members" (Pratt, p. 37). Classrooms at any level of education are often imagined as entities separate from the world around them; yet even schools that have a relatively homogenous student body are not "safe" from clashes of culture. To counter the "clashes" of the contact zone, Pratt suggests the construction of 
what she calls "safe houses": these are places for "healing and mutual recognition... in which to construct shared understandings, knowledges, claims on the world" (p. 40).

While Pratt's concept has been embraced by scholars in composition studies, at least aspects of it have been challenged by others. Joseph Harris (1995), for instance, argues that while Pratt claims to do away with the idea of "a unified and utopian community" by defining the notion of contact zones, she seems to reintroduce this very concept by opposing the contact zone to the "safe house" (p. 34). He further points out that while the contact zone conjures an image of "cultures banging or sliding or bouncing off each other", the "safe house" remains vague, and it is not clear how "one constructs a public space in which members of various 'safe houses' [...] are brought into negotiation (and not just conflict or contact) with other competing views and factions" (Harris, p. $34)$.

bell hooks (1994) addresses diversity in the classroom from a perspective of critical pedagogy. She advocates including "awareness of race, sex and class" in the classroom (the list of identity markers can clearly be expanded). Including such topics, however, brings with it the risk of "confrontation, forceful expression of ideas, or even conflict" (hooks, p. 39). But to hooks, these clashes and conflicts that arise in heterogeneous classrooms are not undesirable, but unavoidable in a "democratic setting", and possibly fruitful. She warns against the frequent misinterpretation of the term "safe" in an educational context: "Many professors have conveyed to me their feeling that the classroom should be a 'safe' place; that usually translates to mean that the professor lectures to a group of quiet students who respond only when they are called on" (hooks, p. 39). In fact, she argues that students may not feel safe at all "in what appears to be a 
neutral setting", thus producing "prolonged silence and a lack of student engagement" (hooks, p. 39).

As a way of overcoming silent spaces of so-called safety, bell hooks proposes to "build 'community' in order to create a climate of openness and intellectual rigor" (p. 40). The way in which she employs the term "community" here differs from the notion Pratt criticizes: to hooks, building community does not imply a silencing of students, but "creates a sense that there is a shared commitment, and a common good that binds us" (hooks, p. 40). Yet "community" as used by hooks implies a goal as to what the classroom and good teaching practice should look like, rather than a concept of classroom space that may serve as a theoretical framework for the realities students (and teachers) may experience on a day-to-day basis.

Linda Flower (2008), in Community Literacy and the Rhetoric of Public Engagement, builds on Pratt's work but takes it a step further. She addresses the "dilemma" educators and scholars face in "figuring out how to construct a rhetorical space that can support transformative relationships", especially with "marginalized and culturally diverse "Others", (Flower, p. 2). Flower argues that "engagement with difference can start in a contact zone where differences are made visible and where assumptions and identities are called into question" (p. 2). While the classroom in such a space can function as "a safe house that nurtures discussion", active engagement requires more than that (Flower, p. 2-3). It needs to take a step further, one that "resists easy consensus, confronts conflicts, and accepts the necessity of civil dissensus" (Flower, p. 3). For community literacy projects in which individuals and groups that hold different interests "clash", she thus develops the idea of "rivalling hypothesis". This concept 
allows for inquiry that aims at acknowledging different perspectives without imposing consensus, which per definition favors majority perspectives over others.

While Flower's work provides a comprehensive framework for community projects, it aims at a conscious use of rhetoric for the purpose of empowerment. Participants are trained to "rival" and learn to speak with others. What I am trying to examine in my study are rhetorical strategies that emerge in institutional settings, strategies participants use in those moments when "clashes" occur - in other words, when systemic hierarchies and power relations inherent to those institutions become prevalent and are felt in one way or another. While Flower's framework may serve to formulate possible goals and solutions, it may not necessarily serve well for the purpose of a description of the ways in which participants grapple with "clashes" in institutional settings. Flower's approach involves training and planning with the overall goal of empowerment; what I am examining is highly contextual, momentary, possibly spontaneous and maybe more reactive rather than active. To summarize, the rhetorics I look at is heavily dependent on Kairos. Therefore, I will proceed to examine a framework that takes precisely such a contextual approach to classroom interaction: Magaret Price's notion of "kairotic spaces".

In Mad at School: Rhetorics of Mental Disability and Academic Life, Price (2011) employs the term "kairotic spaces" to refer to "less formal, often unnoticed areas of academe where knowledge is produced and power is exchanged" (p. 60). The term "kairos" as employed in classical rhetoric is usually defined as "the opportune or appropriate time" (Price, p. 60) and is oftentimes simplified to 'the overall context' of a rhetorical situation. Price highlights that kairos, however, means more than that. It 
"carries ethical and contextual as well as temporal implications" (Price, p. 60).

Definitions of kairos often leave out the importance of access to what Jeffrey Grabill calls "infrastructure". Infrastructure, according to Grabill, "emerges from people in practice, connected to activities and structures" (p. 464). A classroom's infrastructure, then, is more than "its tables and chairs, its technologies, and its participants", but includes different "beliefs, discourses, attitudes, and interchanges that take place there" (Price, p. 61). Thus, Grabill and Price share a common concern: "we must observe - and hopefully intervene in - the unfolding of power relations by means of "studying the unstudied"" (Price, p. 61). "The unstudied" for Grabill are community members outside of academia; for Price, they are "students and faculty members with mental disability" (p. 61).

To define kairotic spaces, Price names five criteria:

1. Real-time unfolding of events

2. Impromptu communication that is required or encouraged

3. In-person contact

4. A strong social element

5. High stakes

However, not all of these characteristics need to be fulfilled at the same time: the boundaries of kairotic spaces are fluid and cannot be "objectively determined" (Price, p. 62). An online discussion between student and professor in which instant messaging is used, for instance, may qualify as a kairotic space. There may not be in-person contact, but clearly, the stakes - for the student especially - may be high in this kind of social interaction. While the student may have more time to respond than in an in-person interaction (which requires impromptu reactions), the expectations regarding correctness 
in written language are likely to be higher than in oral communication. On the other hand, Price highlights that "an informal study session" between two close friends may not qualify as a kairotic space. While this situation does involve personal contact, and the stakes may be high with respect to the results of the study session (if, for instance, they are studying to pass an important exam), the social "risk" is minimal compared to the previously described interaction (Price, p. 61).

The decisive factor is thus the "pairing of spontaneity with high levels of professional / academic impact" (Price, p. 61). In order to understand kairotic spaces, it is not only crucial to recognize the underlying asymmetrical power relations, but also the ways in which different participants may perceive and be affected by them in different manners: while for a professor, a lunch with an advisee implies minimal risk, the student may perceive the conference as a high stakes situation (Price, p. 61-62). Thus, the "importance of kairotic spaces will be more obvious to a person who - for example - can hear only scraps of a conversation held among a group sitting at a table, or who needs more than a few seconds to process a question asked of her in a classroom discussion" (Price, p. 63).

While Price employs kairotic spaces to understand interactions between individuals of different mental ability status, the same may be said for a person who is not fluent in a dominant variety of the language spoken. This is in no way meant to draw a simplified parallel between mental disability and language competency; however, as Price herself points out, kairotic exchanges may be - and have been - studied from different perspectives including "gender, race, class, and specific disabilities" (p. 63). The perspective she employs allows her to challenge common notions of what is considered 
good pedagogical practice, for instance that small discussion groups automatically create a safe space for students (Price, p. 63).

What is distinct about Price's approach as opposed to other conceptualizations of classroom space is that it highlights the rhetorical nature of the encounters that take place: it includes the physical space in which an interactions occur as much as it accounts for participants' cultures, beliefs and values. It allows for an examination of language as much as it other modes of communication. Most importantly, its ultimate concern is not only to "observe", but to "hopefully intervene in" the asymmetrical power relations that are at play. "Kairos", according to Price, carries "ethical implications", and to initiate change is at the core of her inquiry into kairotic spaces in the classroom. Her approach is thus not only in line with Grabill's, but also Flower's and hooks' goals of hearing the voices of the marginalized or as Grabill puts it, the "unstudied". Kairotic spaces, then, may serve as an alternative framework to the contact zone as a conceptualization of classroom space that acknowledges the situational nature of cross-cultural encounters, clashes and interactions.

\subsection{Overview of Theory}

I started out by drawing on the work of the New London Group to point out the importance of a pluralistic paradigm in educational settings. Their approach acknowledges, describes and addresses the realities of students' lifeworlds in world that is shaped by increasing tendencies of globalization and diversification. Their work, and the paradigm they propose, thus constitutes the overarching, "macrocosmic" framework for my research: On the one hand, it provides a perspective on education that takes into account the challenges that arise from "global connectedness" and "local diversification, - 
challenges linguistic minorities are likely to face in educational settings. On the other hand, it offers an overarching goal - a pluralistic paradigm of pedagogy - for scholars, teachers and researchers to strive for.

I then argued that, as I am dealing with linguistic minorities in particular, it is necessary to formulate a paradigm of language that is in accordance with this perspective. It seems that the approach best suited for these purposes is the one discussed by Suresh Canagarajah. Canagarajah understands (grammatical) norms as emergent in practice. $\mathrm{He}$ rejects the myth of monolingualism, but as he outlines the various ways in which scholars describe the diversification of English, it becomes apparent that several of these approaches are still rooted in the monolingual norm. Matsuda as well as Horner et al. show that this norm continues to be perpetuated in the classroom as well; linguistic minorities thus face expectations based on the monolingual paradigm in institutional settings such as the university classroom. The assumption that a stable, monolithic kind of English is "out there", at the top of the hierarchy of Englishes, may lead to the "othering" and exclusion of those who speak a "minority variety". Hence, for the research conducted in this project, it is crucial to keep in mind these dominant, pervasive assumptions on language, as they may impact the ways in which students as well as other "players" in the "institution university" relate to their own and other varieties of English.

Clearly, monolingualism does not correspond to students' translingual realities; the pervasive belief in a monolithic standard necessarily creates a "gap of power" between speakers of "standard" English and linguistic "Others". To describe, understand and analyze interactions that take place in such a classroom space, I am borrowing the term "kairotic spaces" as defined by Margaret Price: this framework offers a 
conceptualization of classroom space that takes into account the high stakes that arise out of (macrocosmic) institutional hierarchies and (microcosmic) asymmetrical power relations between students. It is on the level of kairotic spaces that my research takes place: hence, Price's work is the most crucial for the analysis of my data. Yet I will eventually return to the overarching goal of pluralism and translingualism, and attempt to identify the ways in which my findings contribute and relate to recent scholarship in language and pedagogy. 


\section{Background and Research Stance}

Jeffrey T. Grabill (2012) argues that a researcher needs to articulate a research stance before making choices regarding research methods and goals (p. 215). By research stance, he means "an identity statement that enables a researcher to process methods and make decisions [...] something like a 'position' relative to issues like purposes, goals, and methods for research" (Grabill, p. 215). Grabill asks the researcher to examine her identity - personally and as a researcher -, her purposes, and her commitments with respect to the research (p. 215). While Grabill's focus here is on community research, his argument holds true for other kinds of research: researchers, after all, never come to the field with a "tabula rasa identity". Feminist researchers engaged in the critique of science and technology, such as Sandra Harding, have argued in favor of "standpoint research", an approach that acknowledges a particular researcher's standpoint in the culture she is investigating. Thus, I am taking a situated approach to research as way of recognizing that my identity shapes what the things I observe or hear in the field.

The idea for this project arose out of my experience as an international exchange student from Germany teaching at Michigan Technological University. For this reason, before I start locating myself, I will start by describing the distribution of the student body at this university; this will serve to clarify the situation that international exchange students are faced with on campus.

In terms of its diversity, Michigan Tech's student body is quite unique (MTU 2014): at the undergraduate level, the majority of students are white middle class American males. Both women and - even more so, American ethnic minorities, including African Americans, Native Americans and Hispanics, are underrepresented. However, a 
relatively high number of international students attend the school, especially at the graduate level: in Spring 2014, $15 \%$ of all students enrolled at Michigan Tech were international. At the graduate level, 55\% of all students are international. However, only $4 \%$ of all undergraduate students are international. The number of internationals has increased significantly in the past decade, both at Michigan Tech and nationwide: in 2012, numbers of international students in the United States were at a record high, making up $4 \%$ of all higher education students in the US, with an increase of $7 \%$ compared to the previous year.

What is unique at Michigan Tech is the distribution of graduate and undergraduate internationals; while nationwide, the number of undergraduate students from other countries is slightly higher, Michigan Tech has significantly more graduate internationals. This may be due to the school's focus on engineering; while engineers in the United States are not required to have a graduate degree, companies in European countries as well as China and India differentiate harshly between applicants who hold a Bachelor's or a Master's degree. As a result of this distribution, the majority of all graduate teaching assistants and instructors is international.

Among undergraduate students, about $60 \%$ are in-state residents, most of them from Houghton county, while the remainder of resident students is predominantly from close-by states such as Wisconsin and Minnesota. For these "majority" students, many of whom have been raised in ethnically and racially homogenous environments, Michigan Tech is oftentimes the first space in which they encounter a more diverse population. Several of them have never been exposed to varieties of English other than their own before college education: Michigan, Wisconsin and Minnesota, particularly in rural 
counties, are largely populated by white monolingual speakers of English compared to other states (DTMB 2014). Hence, these students' first prolonged exposure to Englishes previously unknown to them is on campus, in the dorm or in the classroom where, for instance, they may encounter a graduate teaching instructor or classmates whose native language is not (only) English.

International exchange students at Michigan Tech, as the demographics show, are predominantly from "non-Western" countries. I, on the other hand, am from a "Western" country and have no obvious visible identity markers that set me apart from the majority of white Americans. As I explained in my introduction, for a long time I was reluctant to even admit I was German, and I have never seen my language or nationality as an important marker of my own identity. I can disguise my German accent with relative ease, which sometimes leads to confusion: both Americans and students from other countries tend to assume that I am an American, or at least a native speaker of English. I thus recognize that I am in many ways privileged where other exchange students are not. My whiteness, lack of accent, and educational background in a western country allow me to "pass" as American, or at least someone who could be part of the majority culture on campus.

At the same time, my experience in teaching has led me to try and distance myself from the majority culture. In all of the seven classes I have taught at Michigan Tech both freshmen composition and various levels of German language -, the distribution of students in my class reflected the overall distribution on campus. The majority of my students identify as white, male Americans; in four semesters of teaching, I have had about twenty female students, less than ten exchange students from China and India, and 
two African American students. In conversations with those who were a minority in my class, students have often expressed that they struggle with "being heard" in classroom discussions as well as group work. Likewise, I have come across complaints from American students that international students are too "passive", too "silent", and speak with an accent Americans cannot understand. In such moments, without being fully conscious of it, I have always tended side with the minority students, and think of myself as "other". As mentioned earlier, I recognize my own white, Western privilege; however, I have experienced gender-based discrimination throughout my entire education, and it is this experience that has shaped my awareness of bias and exclusion as well as my research interests. To clarify my point, I will give an example.

I especially faced sexism when I studied physics in Germany, which is still a strictly white-male-dominated environment. When I obtained a "B" in quantum mechanics (it was the best grade any student of my class achieved in this exam), I went to the professor's office with my partner to pick up the exam. The professor, without asking, handed the exam to my partner and congratulated him on his achievements. When we explained that it was in fact my exam, the professor in question replied: "Well, I guess it wasn't too difficult after all." There is an extensive body of scholarship including the work of Sandra Harding, Judy Wacjman and Donna Haraway, that addresses the issues women face in the natural sciences. While I have never had to face racism or any form of discrimination other than sexism, having experienced sexism has shaped my awareness of systemic exclusion and, to a certain, limited degree, allows me to relate to other such experiences. It has also sparked a strong wish to pursue research that has an overall aim 
of social justice; however, the project at hand is limited in scope and thus more concerned with identifying what kinds of issues exist. 


\section{Methodology}

The aim of my study is to investigate how students that constitute a linguistic minority in the classroom navigate kairotic spaces - spaces in which direct interaction is shaped by unequal power relations and high stakes. The pervasive belief in linguistic homogeneity both on an institutional as well as on an interpersonal level constitutes the persistence of linguistic hierarchies, in which standard varieties of English are upheld as a standard. Thus linguistic minorities face the challenge of having to assert themselves in a setting where their variety of English is valued less than that of the majority. Out of this context, the following questions are of interest to me: How do linguistic minority students stand their ground, possibly with limited linguistic means available? What strategies do they draw on to prevail against practices of exclusion, oppression and discrimination based on their linguistic differences? What rhetorical means do they employ to navigate the kairotic space?

\subsection{Data Collection}

My fieldwork comprises both observation of classroom interaction and interviews. In order to ensure a sample of participants that is representative of the student body, observation and participant recruitment took place in two sections of first year composition (UN 1015 at Michigan Tech). Composition is a general education class that is mandatory for all Michigan Tech undergraduate students. Because students choose their section of composition most likely because of the time slots available, it is possible that within one section of UN1015 certain majors are over- or underrepresented, since they may have other mandatory classes during a particular time. For this reason, I decided to observe two sections, one in the morning and one in the late afternoon. 
Unlike most other general education classes, composition is structured as a seminar with exercises rather than as a lecture. Students are frequently asked to work in small groups, to perform peer review or to participate in discussions. Hence, student interaction is more frequent in this class than it is in lectures; thus, UN1015 provided ideal conditions for the observation of student interaction.

\subsection{Participants}

In order to determine which students identify as translingual speakers of English, I started out my research with a short questionnaire. While I am analyzing my data with a translingual paradigm in mind, it is likely that students have not been exposed to the terminology, and they a have monolingual / multilingual perspective on language. I thus decided to phrase the questionnaire in such a manner that it did not contain any technical terminology from linguistics. I focused on the languages students were exposed to during their upbringing, languages they were exposed to later in life, as well as their nationality

and ethnicity. Only three students reported exposure to a language other than English. All of the other students were raised in monolingual households and self-identified as white American. All three translingual speakers were international students; American minorities and immigrants were not present. In section 1, one student, Jiang, was male and Chinese, raised in a monolingual household in which Chinese was spoken. Another student, Samir, was male and Indian, raised in a home in which English and Hindi were spoken. In section 2 one female student from China, Liling, reported that she had been raised in a monolingual home in which Chinese was spoken. Both students from China had learned English during secondary education. 
In addition to Jiang, Samir and Liling, both instructors were international graduate students from Ghana. Both were raised speaking multiple languages, English being one of them. As the discussion of Michigan Tech's enrollment statistics has shown, this is not uncommon, considering $55 \%$ of all graduate students are international.

During observation I focused primarily on interactions that took place during group work phases between students who identified as monolingual speakers of English and either Jiang, Samir, or Liling. Group work was the most common form of interaction in section 1; classroom discussion did take place, but in general, few students participated. In part, this may be due to the structure of the classroom, which is tubeshaped and separated into a front- and back section. The back section is set apart with a step and walls that reach further into the room, including a lowered ceiling. This significantly impacts the acoustics of the room; the instructor at the front can hardly hear speakers from the back, whereas it is possible, but difficult, to hear speakers at the front when sitting at the back.

In section 2, lecture was the most common form of interaction. Classroom discussion did not take place; however, the last thirty minutes of class were usually spent in group work. During group work, I would join either one of the three translingual speakers and sit near their groups. Every session I asked all group members whether they would mind me taking notes on their interactions and then remained a passive observer.

In my field notes, I made sure not to focus on language exclusively: I treated group work as a kairotic space, and thus attempted to focus on different modes of communication simultaneously and in context. I tried, as much as possible, to include in my notes gestures, facial expressions, objects and props used to communicate, 
technologies and items that students worked with, proximity between students and physical contact, noises and sounds etc. While I was interested in strategies, I took a bottom-up approach in that I did not use previously designed categories for observation, and I did not code or analyze any data while observing. However, again, I will emphasize my own stance in this project: I did have in mind the concern that translingual students may experience exclusion, and to a certain degree, this preconception is likely to subconsciously have shaped what I did and did not see while researching.

Since Jiang, Samir, Liling and the two instructors were the only individuals who identified as speakers of multiple languages, I recruited the five of them for interviews. Because instructors, in their function as such, are in a more powerful position than students in kairotic exchanges, I initially intended to include their perspective as secondary participants - to supplement and support the data obtained from students. However, since in the case of these particular sections of composition, both instructors also enter the kairotic space as Ghanaian women, and thus constitute a minority in contrast to their students with regards to gender, ethnicity, nationality and the variety of English they speak, I decided to include them both in their function as instructors and as members of a minority in kairotic exchanges.

I also initially intended to include interviews with monolingual speakers of English, yet due to time constraints I decided, with one exception, to focus on linguistic minority students exclusively.

I started my interviews during the third week of observation. They vary in length between fifteen and forty-five minutes. The interviews were semi-structured in that I prepared a set of open-ended questions that encouraged students to talk about their 
experience in narrative form. In order to achieve that, I mainly used the prompt "Tell me about a time when...". The narrative form, I hoped, would yield answers in which participants would speak about specific instances and examples from their experience rather than make general, opinion-focused statements. I chose to elicit "narrative" responses because I am not so much interested in "truths" or "accurate" accounts of situations through which I would then attempt to detect "what really happened"; factors of memory, personal perspective and perception play a significant role in the ways in which we remember, thus a search for truth would not be realistic in this context. However, it is also not necessarily desirable or of primary interest here: rather, I was interested in the ways in which they tell their story, the way they relate to it, the emotions they report on and display while telling it. Rather than specifically ask them to explain the "strategies" they used, I intended to later "extract" the strategies they reported in the course of their story. This, I hoped, would maybe not yield "accurate" details of one specific instance, but the way in which they perceive kairotic exchanges, how they experience them, what motivates them to employ strategies in the first place, and whether they perceive them as successful.

The interviews thus allowed participants to voice their own perceptions and emotions, and discuss contact in kairotic spaces from their own perspectives. As I had anticipated, in many cases, participants' stories would often cover several aspects at once - it was for this reason that my set of interview questions served more as a guideline than a strict template. I let them speak and did not interrupt them, in order not to miss aspects they wanted to bring up: I assumed that if participants felt the need to express something or elaborate on a particular topic, it would be because it was of significance to them. Thus 
I only asked further when they stopped speaking, and then brought up those questions they had not addressed yet.

\subsection{Methods of Data Analysis}

Grounded theory, as Glaser and Strauss (2012) labelled it in the late 1960s, is the "discovery of theory from data" (p. 1). Sarah J. Tracy (2013), whose publication on qualitative research methods served as a guide throughout the process of my analysis, points out that grounded theory is still highly influential in qualitative research, but few scholars "subscribe to grounded theory in its entirety", including herself (p. 184). She uses the term "iterative analysis" to refer to an approach that owes to grounded theory, but "alternates between emic, or emergent, readings of the data and an etic use of existing models, explanations, and theories" (Tracy, p. 184).

The analysis I conducted for this project is very much in accordance with Tracy's definition of iterative analysis. Coding was conducted in three cycles. The combined data of observation and interviews provided such a rich amount of information that II distinguished between three sets of codes on the first level: a) a code for verbal and nonverbal actions, b) a code for themes that arise in dialogue and narration, and c) a code for emotions participants explicitly reported and named. In a second cycle, I conducted axial coding, identifying overarching patterns and ways in which verbal and non-verbal actions, themes and emotions intersected. Finally, in a third cycle of focused coding, I refined categories and built theory based on the emergent pattern.

I used gerund-codes for verbal and non-verbal actions, in order to emphasize their procedural, contextual nature, and highlight that my focus is not practices and activities rather than static, individual statements. These codes were predominantly used to analyze 
the field notes on observation; because the notes were extensive, it was necessary to reiterate the coding process several times. First-level codes include basic (inter)actions on a variety of modes, such as verbal, gestural, aural and spatial: "laughing", "mumbling", "reading", "writing", "turning away", “crossing arms", "using medium" (when participants use cellphones, tablet PCs or laptops). In a revised cycle of first-level coding, I added codes that already included a certain degree of interpretation, such as "asserting", “suggesting", "refuting", “checking comprehension", "requesting clarification" etc.

While many of the observed actions also occurred during interviews, the verbal mode was naturally dominant in this type of data. I did take notes during interviews, but not as extensively, because I noted that active listening (including nodding and short replies, such as "aha" and "okay") encourage participants to keep speaking. Thus, I noted some of the more apparent gestures and facial expressions (for instance when a frown and clenched fists accompanied a raised voice), and coded them according to my initial categories. I also used these codes for actions that were reported in interviews, but marked them as such to distinguish between narrated and observed actions.

Generally, participants tended to reply in narratives and stories. In some cases, their stories referred to events that I had previously observed. Sometimes, the story in fact contradicted what I had witnessed; however, the aim of the interviews is not to arrive at an agreement of what "truly happened". Accuracy of facts cannot be the goal here: several factors - memory, individual perspective and perception, and of course the overall interview situation, which is a kairotic space in itself - shape what participants may say. What will serve as data here is more so the ways in which participants narrate the event, the themes they choose to address and the emotions which they report and display. This 
led me to add two additional levels of first level coding: I coded according to common themes addressed in participants' stories, and according to emotions they explicitly reported. I used nouns to categorize recurrent themes ("education", "culture", "exclusion", "language", "racism" or "diversity"), because this set of codes served to add overarching topics to the previously coded actions, thus nouns seemed more appropriate then gerunds. Some of the themes are in-vivo codes - using words that participants actually used - however, in some cases, participants used synonyms and paraphrasing to express the same concept. For instance, I found that many carefully navigated around the term "racism": while both instructors use it explicitly, students tend to paraphrase it by using expressions such as "being mean to foreigners and excluding them".

I did, however, use in-vivo codes to represent the reported emotions. This seemed appropriate mainly because paraphrasing an emotion may not represent accurately what the person was trying to say; using their own words allows me at least to a certain degree to stay close to what they were trying to express. Furthermore, participants tended to use the same labels for emotion: "uncomfortable", "nervous" and "embarrassed" occurred frequently, whereas "scared" and "isolated" occurred only once each.

In the axial stage, I designed overarching categories that encompassed multiple categories from the first cycle; for instance, I summarized "requesting clarification", "requesting definition" and "checking comprehension" under "clarification". I left the other two sets of categories - "themes" and "emotions" - as they were; rather than find overarching terms for them, I proceeded to investigate the ways in which all three overlapped and related to one another. For example, Instances of reported silence, that in many cases coincided with observed silence, were often reported to be a response to 
"uncomfortable" and almost always occurred either in a story that related to themes of "language" and "exclusion". In the observation data, I did not always have a corresponding story, but verbal and non-verbal actions frequently occurred in combination, and one triggered the other. In some instances, I could also identify the themes which arose in the stories in conversation or dialogue. In this manner, I drew connections between the ways in which stories of specific themes were related to emotions, and ways in which participants responded to them through verbal or non-verbal actions.

In the final cycle, I systematically identified categories which I label "strategies". I am using four overarching categories - "Establishing Ethos", "External Resource", "Keyword Statements", and "Silence" - some of which I divided into subcategories, to differentiate between different ways in which these strategies are employed. Before I move on to the analysis of my data, I will start with an excursion into the concept of "strategy" and justify why I chose this label.

\section{4 "Strategies" as Rhetorical Practices in Kairotic Spaces}

The way I employ this term comes close to what Michel de Certau (1980) in Practices of Everyday Life labels "tactics" (p. 29). According to de Certeau, tactics, in short, are "an art of the weak" (p. 29). A tactic is "a calculated action determined by the absence of a proper locus" (de Certeau, p. 37). By that, de Certeau means that it is a practice employed by an 'other' within the space of the dominant - rather than a form of open resistance, it is an almost playful trickery that allows for a more subtle form of resisting without overthrowing a system in power. As an example, he mentions 'la perruque', a practice employed by workers in the contemporary economy: it is work the 
worker does for herself, "disguised as work for his employer" (de Certeau, p. 5). The worker is on the job, but participates in activities of personal interest; however -to put it in a simplified manner- the worker does not merely engage in this activity for its own sake, but also to tactically trick and subtly undermine the employer.

de Certeau opposes tactics to strategies, which are in turn "the calculation (or manipulation) of power relationships that becomes possible as soon as a subject with will and power (a business, an army, a city, a scientific institution) can be isolated" (p. 36). A strategy is thus employed by a power that claims a space for its own, which is distinct from its environment. Clearly de Certau's work bears a relation to Michel Foucault's here, whose work he critiques for not having sufficiently established how hegemony comes into place through practice. Yet rather than incompatible with Foucault's thought, I read de Certau as elaborating on the ways in which the powers in place come into being through strategies, and are subtly resisted through tactics by 'the common man' at the same time.

I would argue that there are certain parallels between de Certau's concept of practice and the concept of feminist rhetorical resilience, as suggested by Elizabeth Flynn, Patricia Sotirin and Ann Brady (2012). Feminist rhetorical resilience, similarly, is a practice (or, as de Certeau puts it, an art) of "the weak" - in the case of Flynn et al.'s studies, women, particularly women in third world spaces. Flynn, Sotirin and Brady argue that resilience is a powerful metaphor that may serve to conceptualize strategies, actions and choices undertaken by rhetors "in the face of difficult and even impossible challenges" (p. 1). 
Flynn et al. identify agency, metis and relationality as three core concepts of feminist rhetorical resilience. However, they reject traditional readings of 'rhetorical agency' that focus on the rhetor drawing on the best available means and resources to achieve a particular goal. Rather, they stress the creative quality of resilience - resilient rhetors use whatever "comes to hand as suitable" as a rhetorical resource, no matter how unconventional (Flynn et al, p. 8). The resilient rhetor, in an oppressive situation, recognizes and seizes opportunities flexibly and pragmatically. The change that is thus initiated "may not be dramatic or global" but small and local, yet serves its purpose in a particular situation (Flynn et al., p. 8). Thus, similarly to de Certeau's concept of tactics, the resilient action takes place within a system of power that is already in place. Both outline practices that rely on the opportune and whatever is available in a specific context.

Rather than by logic and reasoning, the authors argue, resilience is driven by Metis, a metaphor for situational intelligence borrowed from the classical Greek tradition of rhetoric. It is characterized by "forethought, resourcefulness, opportunism, even deceit" (Flynn et al., p. 9). The idea of "deceit" resembles de Certau's notion of "trickery". Deceitfulness and cunning are understood as non-argumentative strategies of coping with situations of oppression or distress.

Clearly, the two concept of strategies/tactics and rhetorical resilience cannot simply be equated. de Certeau's strategies are not practices individuals engage in; they are institutional, and thus take place on a macrocosmic level. His tactics, then, on a microcosmic level, are what individual workers do in order to do their "own work" within the institutional setting (for instance, the workplace). However, if, to provide a 
contemporary example, a worker is engaging in la perruque by checking facebook on his work computer during work time, this worker is not (necessarily) consciously practicing a form of resistance; the tactic does not aim at "improving" the situation at the workplace, its goal is merely to do what that worker wishes to do during work time. Nevertheless, de Certeau conceptualizes these tactics as subtle forms of resistance that take place within the framework institutional strategies constitute, as the worker is not "obeying" the rules.

Rhetorical resilience, on the other hand, are practices people consciously engage in with the goal to improve one or a few particular oppressive situations. If, for instance, a woman who works in the field of the natural sciences, outwardly displays a naïve, submissive behavior in order to convince her male colleagues to implement an idea she has, making them think it was in fact their idea, she is practicing metus, a form of rhetorical resilience. She purposefully employs her strategy and achieves her scientific goal, thus "improves" the situation, even though she may not obtain full credit (and thus only be partially empowered).

Both tactics and rhetorical resilience offer a framework in which we can understand practices and activities that take place within the order established by the "strong", that rely on the opportune, creativity and cunning that offer agency to the oppressed to address their oppressive situation.

Why, then, did I not choose the term 'tactics' or 'acts of resilience' as a label for the practices that, as I will argue in this section, translingual students rely on in the highstakes situation of the kairotic space? Why choose a term like "strategy", which, in the framework of de Certeau's work, contradicts the notion of tactics? 
As I built theory based on my data evaluation, I came across a broad variety of practices, some of which may fall into the category of "tactics", many of which may also fall into the category of "resilience". However, in order to present my data in the framework of a coherent theory, neither one of the terms captures exactly the essence of my results as a whole. Some of the practices I observe are better described as forms of avoidance, as I will show in my analysis section; one of them is a form of open confrontation: I cannot define them by a particular goal they share. They are all ways of navigating the kairotic space - yet to different ends, and through different ways. Hence, while these practices may be rhetorical, they cannot be summarized under either one of the two terms.

Still, I would like to highlight the factor of rhetorical agency: the practices I may not always be conscious efforts, they may not always have aimed at 'improving' a situation but rather at 'getting out of it'. Yet nevertheless, at least to a certain degree, they can be interpreted as attempts to control the occurrences in kairotic spaces, or find a way around such spaces, with limited means available. Thus, participants, while at first sight it may seem as if they were only struggling, have agency, an agency which they recognize and seize themselves, while they may remain unnoticed to others. I will show that what is often misinterpreted as helplessness, ignorance, or inability - a student's silence, for example, or lack of participation - is in fact a way of dealing with the high-stakes, fastpaced situation within kairotic spaces - with varying degrees of, but possible, success.

I thus propose the term "rhetorical strategy", in the particular context of my research, as signifying a practice participants in this study engage in to address issues that arise in kairotic spaces, which are characterized - as outlined by Margaret Price (2011) - 
by real-time unfolding of events, impromptu communication that is required or encouraged, in-person contact, a strong social element, and high stakes (p. 61). 


\section{Data and Analysis}

I identified five rhetorical strategies as emergent from the data I collected. Before I elaborate on the data itself, I will briefly define and characterize each strategy in terms of its goals, and outline why I chose to include it.

1. Key Questions and Arguments

By key questions and arguments (or "keys"), I mean short, precise statements or questions that participants, when questioned or confronted in one way or another "throw" into the conversation in order to challenge or stand their ground. "Keys" may be incomplete sentences or single words that nevertheless make an argument or "push" the interlocutor to respond. Thus, the participant takes a certain degree of control over the situation. As a matter of fact, only one participant engaged in this practice; while it struck me as extraordinary and efficient, the participant herself felt the strategy to be insufficient, as the interview revealed. I decided to include it here on the one hand because it is unique. On the other hand, the challenges this particular participant faces are significant, and to my mind point to the persistence of ethnocentrism in the classroom.

2. Silence

By silence I mean the refusal to respond to a prompt, to participate in conversation, or to respond with a lowered voice in such a manner that what has been said cannot be heard. This strategy was employed by the three student participants; yet I am focusing on one particular example, namely the participant who engages in this practice the most. I believe the examples I collected from his interactions serve best to examine the multitude of goals this strategy may serve: it appears that silence, for this participant and others, is a form of avoidance (embarrassment, confrontation), a way to 
gain time to formulate a response, but it is also a form of "stubbornness" as a reaction to exclusion.

\section{Establishing Academic Credibility}

By establishing academic credibility, I mean the telling of stories or the mentioning of facts that serve to underscore a participants' ability to function successfully in their respective position in academia. This strategy may include among other aspects a story or statement about one's previous (successful) research or about one's educational background. This strategy has been employed by both student and instructor participants; I am focusing here on one instructor's strategy, because her example seems to illustrate this strategy the best: she engages the most in it, and in the most assertive manner. This strategy differs from all other practices: it is the only one that is confrontational and directly assertive. Nevertheless, this strategy, too, serves as a way of navigating kairotic exchanges; it is for this reason that I decided to include it here.

\section{Circumvention}

By circumvention, I mean the purposeful avoidance of kairotic exchanges in favor of another form of expression that does not involve interpersonal contact. For instance, instead of speaking up in the kairotic space, a participant might choose to instead - or in addition - rely on written forms of communication to express her- or himself. One instructor and one student participant engage in this practice. Both engage in this practice not so much to stand their ground or initiate change, but rather to accomplish a task they need to do: in the case of a student, the completion of a peer review assignment, in the case of the instructor, summarizing the content of class. I chose to present both examples, as this is one case in which an instructor and a participant seem to feel the 
same need to "escape" the pressures of the kairotic encounter; this sparked my interest in this strategy, and I hence decided to discuss it here.

\section{Legitimizing}

By Legitimizing, I mean a kind of behavior that aims at legitimizing one's own variety of English and asserting oneself as a native speaker of English in kairotic spaces. This may include verbal statements that aim at minimizing cultural difference, or "othering" other minorities in order to distance oneself from them. Only one participant engaged in this practice; I decided to include it because it stands out as an exception: it is an assertive strategy in which the participant actively defends and legitimizes his linguistic and cultural identity.

In the following section, I will elaborate on all five strategies and provide examples that illustrate how they are employed and how they function; I will draw on observation and interviews alike to identify the ways in which participants perceive, deal with, and experience the exchange. Whenever possible, I included the emotions participants reported on in interviews with regards to kairotic encounters, as they seem meaningful indicators of reasons and goals of strategies (for instance, they may indicate whether a strategy was employed to address an experience of exclusion, a feeling of helplessness, etc.). I also think that, while an outsider may perceive a strategy as successful and efficient, it can only be labelled truly "successful" if participants themselves experience them as empowering; if they are left feeling angry, helpless, and excluded, it is an indicator to me that some form of intervention is needed - I will discuss possible ways of intervening in my discussion and conclusion. 


\subsection{Key Questions and Arguments}

In section two, I meet Liling, a lively first year student from Yichang, China. She chose Michigan Technological University because of its focus on engineering. "My father says, in his mind, I'm not a girl, I'm a boy." She smiles and places her waistlong hair behind her shoulder. "My father wants me to get a higher education, so I can find a better job. He wants me to have a very bright future. So I decided to come here." The first time I observe Liling, I learned that she studies environmental engineering; in her paper for composition, she writes about the negative effects of nuclear energy. During my first session with Liling, Enyo, the instructor of section two, divided the class into groups and asked them to discuss their research question. Liling is in one group with Mike and Chris; however, Chris is not in class that day. The following dialogue occurred between Mike and Liling:

Liling: "So what is your research topic?"

Mike: "My topic is immigration reform."

Liling (frowns): "What does that mean?"

Mike: "Well - it's about regulating who can come and work in the US."

[Silence. Liling uses her phone underneath the table]

Liling (slowly): "So... there are rules for different people from different countries?"

Mike: "Well - I guess. So for my subquestions, I want to address the history - like with Ellis Island and all that - and then the economic impacts, and culture as well." 
Liling: "So - your question is: Why should Americans support the immigration reform?"

Mike: "No. It's hard to say - I'm not saying that all these people are wrong, but-" (italics indicate emphasis in tone)

Liling: "I don’t really understand."

Mike (mumbles): "Well ... it can cause [mumbles, inaudible] But economically, there are also benefits."

Liling: "Benefits?"

Mike: "Well, Sweden for example is one of the top exporters of technology and science, and so they benefit the world."

The conversation is stopped at this point as the class is over. It seems that Liling is skeptical when Mike names his topic. Her frown indicates tension; it is likely that she know the term "immigration" - a term that students on F1 Visa frequently come across but she asks Mike to specify what "immigration reform" means. In the interview, she tells me that she also looked up the term on her phone. She then somewhat tentatively whether immigration reform has to do with "rules for different people from different countries"; in her next turn, she asks Mike to specify his research question. Her facial expression and tone show discomfort, and her repeated questions and requests for clarification indicate that she is trying to find out whether Mike is implicitly attacking her by bringing up immigration reform. As she asks "So - your question is: Why should Americans support the immigration reform?" is phrased in such a manner that Mike, in response, will have to comment on whether he supports the reform. He replies in an evasive manner: "No. It's hard to say. I'm not saying that all these people are wrong, but-". Mike's evasiveness 
indicates discomfort; he is defensive ("I'm not saying..."), and seems to avoid stating his opinion on the matter in front of Liling, who pushes him further to elaborate: "I don't really understand." Mike then starts to mumble, and his full statement is inaudible. At this point, it is quite apparent that whatever his position, it is likely in favor of restrictions to immigration. His voice rises again as he brings up the counterargument to what seems to be his own position: "But economically, there are also benefits." By repeating "Benefits?" as a question, Liling pushes Mike even further to elaborate, whereupon he explains that "Sweden", with its development and technology, "benefits the world". The implication in this statement, however, is that there are countries who do not benefit the world.

For both participants in this kairotic space, the stakes increase throughout the course of the conversation: Mike realizes that he cannot discuss his research topic in the same manner that he can discuss it with other Americans, and becomes aware of his audience after the situation has already become tense. For Liling, it seems, it is difficult to respond: at least in the beginning, she seems to wonder what is happening - what is Mike's stance on immigration reform? Her questions do not merely relate to her understanding in terms of language: she uses them to push Mike to make a statement, to expose his stance on immigration reform - which he seems to perceive as he becomes ever more evasive and defensive.

In this complex and tense situation, Liling uses what I call "keys" - short, to the point questions or arguments - that, under the time- and social pressure of the kairotic space, serve the person who faces the higher stakes to gain higher ground. Clearly, Liling is at a systemic disadvantage in her composition class: not only is she one out of only two 
women - and a female engineer-, she is also the only Asian (in fact, the only person who is not white and Caucasian), and a translingual speaker of English. She tells me that she has learned English relatively late in life, that she did not have much time to prepare for her study abroad while in China, and reports that her accent is a concern for her that impacts her confidence to speak.

Her questions and statements - "What does that mean?", "I don’t really understand" - allow her to put Mike on the spot without explicitly having to bring up the issue of racism, or defending herself: she put him on the defensive side with only a few words, thus challenging - if maybe not overturning - the power relations in this kairotic space.

An occurrence a week later will serve to further illustrate the role of these "keys". Enyo asked her students to peer review their annotated bibliographies for the research paper. Liling is still in the same group; this time, Chris is there, too. Neither Mike nor Chris have submitted annotated bibliographies, so the group is only reviewing Liling's sources.

Mike: “Aren’t these all databases?"

Liling (with emphasis): "Yeah, all."

Mike: "These are all credible I think"

Chris: "And they are all really current."

Liling:"Yes, I only use current sources."

Mike: “Well I mean, you're anti-nuclear energy ... but... it's actually not that dangerous, right, I mean, is it? [looks at Chris]

Chris: "No it's not..." 
Liling: "The waste is hard to deal with"

Mike: "What? The waste - is that what you're saying? Yeah the waste is bad."

Liling: "And Fukushima."

Mike: "Yeah, that was..."

Chris: "That was bad..."

Mike: "But there is no station that could cause so much damage as in that location."

Chris: "It was the location."

Liling: "Also, the radiation is really awful."

Mike: "Well, they evacuated the area, but the water breached - it was okay as a facility, it was just not ready for a natural disaster."

Chris: "That's like - every station."

Mike: “And with Tschernobyl. There wasn't even a nuclear physicist on staff, just an electrical engineer, and they were just testing - like a case study - or was that the other one, I always forget. But yeah, your sources."

Mike and Chris seem impressed by Liling's choice of sources. With only two words, on which she puts emphasis by speaking loudly and clearly, Liling reinforces the reliability of her sources by highlighting the fact that she used databases ("Yeah, all"). She gives further emphasis to her credibility as a researcher by stating that she only uses current sources. Yet Mike nevertheless quickly changes the subject from the credibility of her sources to the accuracy of Liling's thesis that nuclear energy is dangerous. He seeks the confirmation of Chris ("right, I mean, is it?"), who agrees with Mike. 
Again, Liling, as a female Asian translingual speaker of English, faces the highest stakes in the kairotic space. The exchange is fast-paced, and Liling, whose ability to judge the impact of nuclear energy is doubted by her peers, needs to respond quickly and precisely.

With three short, precise statements, - keys -, Liling makes three arguments: she mentions nuclear waste, nuclear disasters, and the effects of radiation. Mike seems surprised when she responds "the waste is hard to deal with", and has to acknowledge her argument. Before he can respond with a counterargument, Liling mentions one key word - Fukushima - that in spite of its brevity serves her as both argument and evidence in the form of an example. Again, both Mike and Chris have to acknowledge her point: "that was bad". However, Mike then characterizes the Fukushima incident as an exception, arguing that the amount of damage was due to location. Liling, reinforcing her previous argument about nuclear disaster, then brings up the radiation. Mike counterargues that this was only because the station "was not ready for a natural disaster." Chris, however, then sides with Liling, pointing out a logical fallacy in Mike's argument: no station is ready for disaster. Mike starts to bring up another example to support his point, but then realizes that he is not sure about his evidence: "or was that the other one, I always forget." At that point, he changes the topic back to sources, and it seems that he gives up the argument: with three "keys", Liling has argued her point; it seems that Chris, at least to a certain extent, was convinced, and Mike has realized the evidence available to him at this point is insufficient to refute her.

In her interview, however, Liling reveals that she is not satisfied with the way she argued in either one of the two situations: 
“That day, Mike and I talked about our topic. I talked about nuclear energy, and he talked about immigration reform. And at first I didn't know exactly what that means. I just listened to him. Then actually, I used my phone to look it up, and then I knew what it means, and there, I thought - he said this to ME! Like I'm going to immigrate to his country, and he doesn't want me to! And when I talked about nuclear energy, he just refuted everything about me. And I think it's very shame, but I can say nothing. I feel very embarrassed. Because if he knew Chinese, I can say EVERYTHING EVERYTHING to refute him, but actually I'm not very familiar to the culture here, so...I don't know if he is just mean, or if he just want to write about it. So I can’t say nothing to him.” (capitalization indicates a raised voice and emphasis on the words here)

Liling, at this point in the interview, is furious: her voice is raised, and I can see that her hand is clenched around the microphone. Her anger, frustration and perceived helplessness, especially in the first group session with Mike, overshadow the way in which she mastered the situations. Her "keys", then, are not a conscious effort; she did what occurred to her in the moment, but in her eyes, it was insufficient. Liling is confident with regards to the subject matter; the issue, to her, was language: "if he knew Chinese", she feels that she could have refuted him easily. I spoke with Mike as well, and he referred to working with Liling during his interview:

“There's been some instances where communication hasn't been as ...key. I feel like some stuff goes over her head sometimes [...] We were peer reviewing some papers as well. We were talking about her subject, and her subject was nuclear 
power. And how it's good. Well, I thought, she was supporting nuclear power, but the whole time, she wasn't. It's just...went over my head, and I think it went over her head what I was saying as well... so I mean there's always a little bit of confusion, but I think after you're past that, you really make some progress I guess."

Judging from Mike's statement, "I feel like some stuff goes over her head sometimes", it is possible that he assumes Liling did not understand his English, considering especially that he presents the dialogue on nuclear power as a misunderstanding. He argues that both he and Liling were overwhelmed with the situation, but ultimately draws a positive conclusion - "you really make some progress" and it is not clear whether that relates to Liling, himself, or both of them. It is generally my impression that Mike, particularly in the conversation on immigration reform, realized that he needed to pay attention to his audience; his awkwardness reveals insecurity, and clearly, he lacks the rhetorical skills to discuss the topic sensitively. After all, however, Liling leaves the situation feeling excluded and helpless, whereas Mike can move on and even - at least according to the interview - reflect back on the experience positively.

\subsection{Silence}

Jiang is the first participant I meet, and the first one I interview. He comes across like a quiet, shy young man, and while he agrees to be interviewed, I can see that he is not entirely comfortable with the idea. On the morning of the interview I ask him if he is okay, whereupon he tells me that he is "a little nervous". I tell him that this is my first 
interview, and that I am a little nervous as well. Jiang smiles and helps me set up the recording app, as I explain to him what I would like to talk about.

Jiang is a second-year student from Changsha, which is located in the Hunan province, China. By the time of the interview, I have been sitting with him or his group for two and a half weeks - five eighty-minute sessions of Composition, that is. During that time, Jiang has hardly spoken a word. The following dialogue occurred after an individual warm-up writing assignment; the setting is a classroom discussion led by Izegbe, the instructor.

Izegbe: "Jiang, what do you have?"

Jiang: [shakes head, holding a pen in his hand]

Izegbe: "You didn’t finish?"

Jiang [nods]

Izegbe: Okay. Finish it now. I'll come back to you later.

In this exchange, Jiang does not speak at all, and responds to the teacher's questions with body language. However, Izegbe understands what he is saying - the combination of him still holding a pen and a shake of his head indicate to her that Jiang is not done with his writing exercise. She uses what I called a 'comprehension check' in my code (“You didn't finish?") to make sure she interprets his gesture correctly. While Jiang remains silent throughout this exchange, he nevertheless successfully conveys a message: I need more time.

The following exchange occurred when students were asked to discuss their research topics in groups; Izegbe walked from one group to the next and students reported back to her. Izegbe: "What's your research topic, Jiang?" 
Jiang: [inaudible]

Izegbe: "What? You need to speak up."

Jiang: "How do people deal with peer pressure."

Izegbe: "How do what? People?"

Jiang: "Deal with peer pressure."

Izegbe: "Deal with - peer pressure?"

Jiang: [nods]

In this dialogue, Jiang responds with speech, but his voice is too quiet for Izegbe to hear. She requests clarification three times; the third time, Jiang only repeats the part that Izegbe has not picked up yet ("Deal with peer pressure"). Finally, upon Izegbe's last comprehension check, he uses body language; she has correctly picked up what he has said, and there is no need for him to repeat it.

Both instances show Jiang's responses use a minimal amount of verbal communication. The first occasion as well as the last turn of the second dialogue show that if possible, he avoids it altogether. Both settings are examples of kairotic spaces. In both events, an in-person conversation takes place in real -time, and an impromptu response is expected from the participants when asked by the instructor. The time pressure thus is high, and so are the social stakes for Jiang, who is singled out to read his response to the class in the first case, when he is not ready for it.

In the interview, Jiang comments on his situation in the class:

"I can tell you two stories - in one, I feel comfortable, but in one, I feel not very good. So if I - usually if I have a short conversation with somebody, there will be some mistake, because I can't explain my, like, what I want to express very 
clearly. Because time is limited, maybe I just have one second, two seconds, maybe the people don't understand me too much. But when I sit here with somebody, like when I was in ESL program, I had to speak to a foreigner, every week, like one hour, and then I have enough time to explain what I mean. Maybe I will make some grammar mistake, like, sentence incomplete, but they will know. So that makes me comfortable, we can talk to each other very good. But, like, usually the short conversation - maybe like some teacher asks me a question in class, I don't have too much time to speak, and I'm nervous, it makes me embarrassed and uncomfortable."

Clearly, one of the situations Jiang describes is that of speaking in a kairotic space: he mentions time pressure ("time is limited, maybe I just have one second, two seconds") as well as the social pressure, especially the fear of losing face ("maybe people don't understand me ... I'm nervous, it makes me embarrassed and uncomfortable"). He recognizes that he is in a high-stakes situation ("some teacher asks me a question in class"), thus he wants to express himself "very clearly", but the context which he is in requires an impromptu response. However, when in a situation that may not qualify as a kairotic space, or at least not a high-stakes one - an ungraded, casual weekly meeting with a student-tutor, who is aware of Jiang's status as a learner ("but they will know") - Jiang reports feeling comfortable. His response itself shows that this is indeed the case: "But when I sit here with somebody" seems to refer to the interview; while clearly, a recorded interview may qualify as a kairotic space, I had initially emphasized that it will not impact his grades, that I will change his name, and that he can take time to think whenever he wishes to do so. While saying that may not completely 
change the fact that he is opening up to a stranger, he seems to have taken my word: his voice is clear and much louder than in class, and his sentences are long and elaborate.

Jiang chooses to be silent, to give short responses and lower his voice under the pressure of the kairotic space; he thus avoids what he perceives as discomfort and embarrassment. Silence, he tells me, gives him time to think in group work as well as in classroom discussion. "I know it's not a good way", he says, but according to Jiang, it is not uncommon: "Chinese people always just sit and do not talk too much [...] - this doesn't mean they don't want to. [...] we don't do the group work in middle school, in high school, we're not familiar with this." Jiang argues that kairotic spaces were not part of his education in China; he is used to lecture based classes, and he feels unprepared to deal with fast-paced interactions, especially in a foreign language: "In my ESL program, we started to do the group work, but usually it's with my Chinese friends." In the ESL program, Jiang says he could enjoy group work, and "make jokes, like the Americans". For them, he argues, it is easier, "they speak their language, they already have their jokes" (my emphasis here corresponds to his tone). Even though he does not explicitly say so, his statement seems to indicate that silence is his is also response to a sense of being excluded. The way he ends the interview further enhances the impression: “Nobody asks us, why should I talk? And they're talking, why should I interrupt? And how can I join them, what should I say, and will they understand me? These are all the questions in my head."

Jiang identifies both cultural and language-related issues that make kairotic spaces a particular challenge for him. Silence is his response and way of addressing this challenge, and it serves at least two purposes: he avoids what he perceives as 
embarrassment, and he gains time to think. There seems to be a certain bitterness to his tone when he says that "nobody asks us, why should I talk?" It is my impression, then, that Jiang's silence is more than avoidance: his statement can be read as an implication that others should acknowledge how challenging the situation is, and thus make an effort to include him in their conversation. It is Jiang's silent form of protest in the face of feeling excluded; his silence is not arbitrary, it is rhetorical.

\subsection{Establishing Academic Credibility}

My interviews with Izegbe and Enyo were designed to include the instructors' perspective. This, I thought, was of particular interest, because both instructors are Ghanians; as translingual speakers they might, I thought, be able to relate to the experience of their translingual students. Throughout the interviews, however, I realized that they, too, found themselves as minorities in a kairotic space, and while their positions as instructors put them at the powerful end of the kairotic space, they were not part of the dominant group their students consisted of. Izegbe addresses her experience as an African woman teaching in a US classroom:

"Even before I started teaching [...] they gave us some statistics that the majority of the students coming here haven't really interacted with people outside their place. And for me, I was very scared. Well, I got to the class, I said hello, introduced myself, and before I listened to them, where they were coming from, I told them about myself. I told them about where I come from, I told them the class theme was diversity, and I told them that this class was going to be a mutually understanding class, there's international students in the class, there's me, there's you, who come from different states of the country, so we have to 
accept each other. I won't tolerate discrimination, I emphasize respectfulness. So even before they spoke, I just laid the ground. I also showed a video of a Nigerian writer and speaker, and I think after the video it dawned on them. They were just mesmerized. They had this pretty black African woman spoke eloquent, fluent, flawless English, and she touched on so many things. [...] And so, at the end, they were overwhelmed, they were mesmerized, they were touched. I had them write a response on the video, and the reviews were good. So then right from day one, I had it cemented in their heads, and each of us said where we are coming from, what they were interested in, so I think that right from the beginning everything started warming up."

Izegbe is an African woman in a male-dominated, white environment, working with students who have not interacted much with foreigners. The authority that, at a school such as this one, is automatically granted to a white male professor is not available to her. Initially, she is "scared", knowing that she does not share the characteristics of the dominant group in this environment, and thus needs to establish her authority. Hence, Izegbe reports that she started teaching by "laying the ground" - making a clear statement on racism and intolerance, and explicitly addressing issues of diversity, which is also the theme of her class. She purposefully speaks from the perspective of an African woman teacher and claims that space, thus taking a situated, contextualized approach to teaching.

The video of the Nigerian writer and speaker serves as an example of another female African intellectual; additionally, it serves to broaden students' perspective and helps Izegbe show the academic achievements of Africa, underscoring her ethos as a 
scholar. It also serves to further emphasize the value of her perspective, as one that may bring insights students are not familiar with. Izegbe in this manner claims her place as an instructor in the kairotic space and as an expert on her culture. Thereby she establishes her authority and ethos as a scholar.

An example from her class shows the way in which Izegbe continues to implement this strategy. Izegbe, at this point in her class, is discussing how best to recruit and interview participants in a study. She summarizes her arguments in a PowerPoint slide, which displays ten crucial aspects a researcher should be mindful of. She elaborates on each point by either drawing on an example from her own research, or by drawing on the work of other Ghanaian scholars. In the process, Izegbe often confronts students with facts and stories they have not heard of before and that "shock" them. This is a method Izegbe frequently employs in her class; the following two points are exemplary for what she does:

"Be sensitive. Some people might prefer an interview over the phone. When I did research for my undergrad, I looked at fgm. What is fgm? [students shake their heads or shrug] Female genital mutilation. There is a tribe in the north of my country that believes that when a girl comes of age [...] you take a razor blade and cut off her clitoris. No sedation [students respond with shocked facial expressions and exclamations indication pain] [...] For my research, I finally found one person who was willing to talk about her experience, but only over the phone.

Also, offer something to your participants. There's this journalist, Komla Dumor, he's from Ghana [she shows pictures of Komla Dumor]. He went to do a story in Kenya. So he wanted to interview this woman [she shows a picture of the 
woman], but before he got to interview her, she asked him to carry these gallons home for her [she shows a scene of Dumor carrying gallons]. So depending on who you interview, you also need to do something for them. Mind that this is different from bribing."

In the first case, Izegbe is elaborating on the importance of being sensitive during research. She draws on her own research on female genital mutilation. Students have never heard of fgm before. They are shocked, an effect further enhanced by the way in which Izegbe introduces the topic: She is very direct and uses short, clear sentences such as "no sedation". She thereby triggers an empathetic reaction, as students respond with facial expressions and sounds that indicate pain, as Izegbe describes the procedure of fgm in detail (I shortened the extract significantly). Izegbe's example serves multiple purposes here: mainly, she aims at illustrating that sensitivity towards participants in research is crucial. This she achieves by choosing an inherently sensitive topic and presenting it in a manner that causes students to imagine the pain fgm victims' experience. At the same time, she raises awareness to the existence of fgm. Finally, she draws on her own scholarship to assert her expertise as a researcher: she has done field work on a highly sensitive issue that is clearly difficult to address, psychologically and emotionally, and has succeeded in gaining the trust of a participant.

In the second case, she emphasizes that researchers have a responsibility to ask themselves how they can benefit their participants. She draws on another example from Ghana, this time presenting the work of the Ghanaian journalist Komla Dumor. She tells his story using images, among them an image that shows Dumor aiding his participant, 
carrying her water. Thereby, Izegbe not only exemplifies and visually illustrates the responsibilities of researchers, which is the primary purpose in this case, she also encourages students to recognize academic contributions in countries outside of the US. In addition to that, she displays her own knowledge of existing research: this is especially effective considering Izegbe uses examples such as this one frequently and whenever she introduces a new concept.

In this manner, Izegbe asserts her authority as an instructor and her credibility as a researcher in the kairotic space of the classroom. Whenever she draws on her own expertise and knowledge, she presents an example that proves her engagement and critical understanding of the topic. At the same time, she uses these opportunities to broaden students' horizons and present to them thoughts and ideas they are unfamiliar with. All of this, however, takes place as part of her overall teaching goals, and thus she weaves her strategy of asserting academic credibility into her curriculum.

\subsection{Circumvention}

Enyo, the instructor of section two, is a PhD student from Ghana. She tells me she has taught extensively in Ghana, but the experience she is making in the United States is quite different.

"When I was in Ghana, I was used to so many black people being around because we are all black [...] of course, I also saw white people [...] But when I came here, I realized I was in a minority. It was almost like a flip for me: all of a sudden I had moved from being in a majority to a being in a situation where I was in a minority. [...] I was much more confident as a teacher in Ghana [...] I tend to be very provocative and political. I am not in my class here, because I am not so 
sure how my comments will be taken, and I don't really understand where my students are coming from. I'm also very new to the system, and I don't want to say - I think I'm just not as comfortable as I used to be when I was teaching in Ghana."

In Ghana, Enyo was part of a majority group; when she taught, the stakes she faced in the kairotic space of the classroom were low, she felt confident to be "provocative and political". The experience of being in a minority is new to her, the context she finds herself in forces her to renegotiate her identity, and it impacts her confidence when teaching in the United States. Additionally, she is concerned that political or provocative comments might be perceived differently in American culture, an environment to which she is new. Thus, the "flip" from majority to minority is, at the same time, a (perceived) switch of her position in the kairotic space as a teacher, and it seems that she is highly conscious of it. Her accent, she reports, is an additional concern for Enyo. She has noted that some of her students tend to whisper, and she finds herself wondering if her accent is an issue to them.

"I use a different accent from the accents that they are used to, so sometimes, I say things, and they whisper. For instance, I used the word "massage". I was talking about massaging sources. I said, “Don't just take somebody’s ideas. Massage it a bit". [...] I was used to using the expression 'massage', and when I used it, one of the students whispered, and then he said: “That was a very strange expression." It was okay, but what about the other situations, in which I didn't know what they said? Then again, I don't want to be all negative, but I really, really wanted to know what they are thinking (laughs)" 
Enyo tells me she was raised in an educational setting that was shaped by British influence; American students are unfamiliar with some of the terms she uses, and her accent differs from the Midwestern accent that is commonly spoken at Michigan Tech. The case above is one in which a student in fact commented on her use of an unfamiliar term, but Enyo is more concerned with "the other situations" in which students whispered and she did not know what they said. Whispering, it may be argued, is common among students and often not related to the teacher; Enyo acknowledges that ("I don't want to be all negative"). Analyzing this issue when keeping in mind that the concept of kairotic spaces may reveal a different interpretation: in a classroom, the stakes are traditionally higher for the student, as the student is being evaluated by the instructor, who ultimately, in any form and type of classroom, will ultimately judge the students' work. The "kairos" thus implies a set of rules - such as who gets to speak, and when. Whispering while the instructor is speaking, even if unrelated to the class, is a form of challenge to the imposed structure, and the authority of the instructor. Parallels can be drawn to de Certeau's notion of tactics, especially his example of la perruque: while de Certeau speaks about workers who "break the rules", using work time to actually perform work for themselves, students doing "other work" in the classroom may be doing something similar. However, as de Certeau emphasizes, the aforementioned workers do not so much challenge an individual by "breaking rules", but rather resist the rules that govern whatever institution or system they are in. Furthermore, this challenge my not be conscious. Similarly, students may not try to challenge an instructor, or criticize the content of a class, by breaking the discursive rules; but they might use it as a way to respond to aspects of the university as an institution. They might respond to the pressure of having to pass classes, 
which they perceive as stress, by using class time for 'doing their own work'. From Enyo's perspective, it is difficult to pass a judgment on the function of the whispering. While she knows it may not be related to her, she says that "all of sudden, I become very conscious". She experiences the kairotic space of the classroom in the US as a previously unknown challenge. She meets it by taking communication outside of the kairotic space: "I tend to send emails after class, to kind of retrace what I did. [...] When you speak, people have to deal with accent, and sometimes people don't want to stretch themselves and they don't get what you say. But when you write, there is nothing like accent in writing. So what I tend to do is I send them an email, reminding them of some of the things I want them to take note of."

Note that Enyo is not concerned with her accent as being the issue; the problem, to her, is rather that "sometimes people don't want to stretch themselves"; the listener may have to make an effort to listen, and Enyo's students, she fears, may not be willing to do so. Still, she makes the effort of writing emails to them, which clearly costs her a significant additional amount of time.

Writing thus allows her to reach all students, including those who are not willing to "stretch themselves"; the kairotic space, which in this case is characterized by spoken interaction, is thereby circumvented. Writing emails also circumvents the time constraint the kairotic space imposes, as well as the high stakes of social interaction: it gives Enyo distance, time to carefully phrase her text, and it circumvents the discomfort she feels when students whisper.

I will provide a second example illustrate how participants made use of circumvention as a strategy; this following instance shows even more clearly how 
participants use writing to express themselves by navigating around the kairotic space. Students in section 1 were asked to peer review each other's annotated bibliographies by writing comments to each other. Before these comments were handed back to those who they were addressed to, Izegbe asked several students to orally report to the class what issues they had encountered with their peers' sources. Jiang, the second year student from Changsha, evaluated the sources of Erik, a student whose paper dealt with the effects of standardized testing on students:

Izegbe: "Jiang, whose source did you peer review?"

Jiang: [inaudible]

Izegbe: "Who?"

Jiang: "Erik."

Izegbe: "Who, Erik? And what were some of the problems?"

Jiang: "No problem."

Izegbe: "You did not find any problem?"

Jiang: [inaudible]

Izegbe: "What?" [Walks over to stand next to him] "Again."

Jiang: “...five sources... stated the purpose of each source...”

Izegbe: "Okay, so he stated the purpose of each source. And were you convinced?"

Jiang: "Yes."

Izegbe: "No problem whatsoever?"

Jiang: "No." 
At this moment, I was sitting next to Jiang. I asked him if I could see the peer review response he had written, and if he would allow me to take notes on its content. $\mathrm{He}$ agreed, and in his statement, I read the following response to one of Erik's sources:

"I'm not clear as to what the usage of the second source is. It's about correlations in statistics of teacher's views; how does this source show the effect of standardized testing on students?"

The response is evidence that Jiang did have a point of critique with regard to Erik's sources, which he expressed and justified clearly in his peer review. However, when Izegbe asks him to report on the results of his peer review, he responds - as shown previously in the chapter on 'silence' - with short answers and a quiet voice, and claims that there is "no problem". Again, as previous examples have shown, he keeps his response minimal to avoid what he perceives as embarrassment in the kairotic space. He has fulfilled the task he was asked to do in writing: he has given Erik meaningful feedback, and he also knows that Izegbe will eventually see the response in Erik's portfolio - so his grade in class is not at risk. Thus, there is no urgent need to give a more extensive answer in the kairotic situation of open classroom discussion, which would mean risking embarrassment and discomfort. Jiang has successfully circumvented the kairotic space by giving preference to the written mode over the oral mode, which spares him the time constraint and social pressure of the kairotic space and yet allows him to complete his task. His use of circumvention is similar to that of Enyo's because part of the motivation for a "switch of mode" is the fact that they both speak a variety of English that differs from the norm in class. However, Enyo's main motivation is to fulfill her duty as a teacher and reach all students, whereas Jiang perceives speaking in kairotic spaces as 
potentially embarrassing. Nevertheless, both employ the same strategy, even though they strive to achieve different goals.

\subsection{Legitimizing}

On my first day of observation in section 1, I sat down in the back of the class. As I observe the lesson, Samir is one of the first students I notice. He sits at the very front of the classroom, together with his group members, Jonathan, Tom and Kelly. I hear them laughing and joking, but I cannot hear what they say.

Samir comes across as a lively and cheerful young man. He is a first year student from Gwalior, which is a district located in the state of Madhya Pradesh, India. "Madhya Pradesh is Hindi for Central State; Madhya means central, Pradesh means State. Madhya - Pradesh", he pronounces it slowly and nods in my direction - he would like me to try to pronounce the words. I try, and he nods: "Yes, that was good!" he encourages me. Samir, I can tell, is excited about the interview. When I start to prompt him to tell me about where he comes from, he immediately takes over, tells me about India as a country, its languages, his state, his district and his family. It seems as if he has been waiting for someone to ask him about his home. "You see, in India, every culture can speak the language they want. No one is bound to say that Hindi is their native language. You have a choice", he tells me. His tone is enthusiastic: he praises the 'official' recognition translingualism in India and implicitly contrasts with other cultures (America being one of them), where translingualism is present, but not embraced or officially acknowledged.

The way in which Samir - implicitly - contrasts India with America surprises me at first, as they seem to contradict what I have observed. It is only during coding that I start to make sense of what he is doing. In my observation, when interacting with his 
group members, Samir displays what appears to be a different viewpoint. In most sessions, when the group is done with their task, Tom or Kelly change topics, and often ask Samir questions about Indian culture. The following response is exemplary for Samir's reactions to these questions:

Tom: "So how's Bollywood different from the American film industry?" Samir: "Really, there is no difference. It's just that we have Hindi as a language over there, you have English as a language over here, you've got certain... you've got all kinds of technology in your film work that creates effects, we don't have as much. Still, we have a lot of good movies. Bollywood is just amazing." While his group member's questions may arise out of genuine curiosity, they single out Samir as an expert or representative of Indian culture. Thereby, consciously or not, they set themselves apart from him, drawing a "cultural line" between themselves as Americans and him as Indian, which may be perceived by Samir as indicating that he is not one of them, he does not belong. In his response, Samir puts the emphasis on similarities between American and Indian culture; in fact, he claims there is "no difference'. He mentions two aspects in which the two industries differ, language and technology, but denies the existence of any other distinct (cultural) features. At the same time, he also puts emphasis on the quality of Bollywood films. It appears that he wants his group members to appreciate Indian culture ("Bollywood is just amazing”), but feels the need to minimize difference in order for them to approve of it.

Towards the end of the interview, he reports on a similar incident. He tells me about his first meeting with his enterprise team, in which the team assigned 
responsibilities. The other three members asked him if he was familiar with AutoCAD and Matlab.

"I told him that I don't have any sort of experiences in that, so [...] he asked me, what kind of school do you have in India? He was not insulting me actually; he was just kind of asking simply, what kind of school do you have in India. And I told him that we just have schools where you go study certain subjects, the same kind of school you have, it's just that the variety of courses is not as well as you have it here."

While Samir emphasizes that his group member is not "insulting" him, it still seems that he feels the need to defend his education. Even though Samir reports that his team member "was just kind of asking simply", the question in this context implies an assumption about the Indian school system (that it is "lacking" something compared to the American system). Samir seems to sense that, and highlights that the difference lies in the variety of courses, not in the quality of education. Again, Samir wants his team members to appreciate his cultural background, and defends it by highlighting similarity. Yet he is also defending his team member in the interview: it appears he tries to highlight his good relationship with his team mates.

When I ask him to tell me about interactions with speakers of different English varieties, he tells me the following story:

"I have lots of trouble understanding the English spoken by the Chinese. [...] They do have their own accent - I'm not insulting anyone - but they do have their own accent [...]. So I do have a lot of problems understanding their accent." 
Samir singles out the Chinese as having "their own accent". He phrases it carefully ("I'm not insulting anyone"), but it seems as if he identifies them as a group distinct from a majority that he is part of. He thus - at this point, at least - seems to identify himself as a native speaker of English, as he was raised with it as a first language, distinguishing himself from those who learned English as a second language. It is my impression that Samir is trying to present himself as part of the linguistic majority, as a native speaker of English: he minimizes difference between American culture and his own, defends and emphasizes his friendly relationship with his American team members, but sets himself apart from Chinese students, which he presents as a (the only) linguistic minority. His efforts thus serve to legitimize his own variety of English: he wants others to acknowledge that he, too, is a native speaker, that English is part of his identity, and that thus, he does not fall into certain categories as other international students do.

Samir wants his American peers to acknowledge the similarities they share in terms of language and culture. In kairotic moments in which others - for instance, group members who identify as American - single him out as an "expert" of his culture, he responds by pointing out similarities, thus emphasizing his belonging and legitimizing his variety of English. In the kairotic space, he is put on the spot and expected to give a response which is "true" for all of his culture. While his group members may not at all intend to exclude him, he wants them to acknowledge that he - as an individual - is part of their group, that he "belongs". He also wants them to value his culture as much as they value their own; hence he emphasizes similarities and tries to protect himself against exclusion and the sense of being an outsider. 


\section{Discussion}

I started out my research by asking how translingual students navigate kairotic spaces. Altogether, I have identified five rhetorical tools that I have labelled "strategies" which participants in this study use to meet challenges they encounter in kairotic moments.

The term "kairotic space" I have borrowed from Margaret Price, who uses it in order to describe ways in which students of various mental ability statuses navigate these situations. Price (2011) thus takes one particular approach to kairotic spaces, while acknowledging that such exchanges may be studied from various perspectives, including "gender, race, class, and specific disabilities" (p. 63). The research presented here may thus be seen as adding to Price's studies in that it adds the perspective of linguistic minorities. As I have previously emphasized, I have no intention of simply comparing or equating students of different ability statuses and students who are part of a linguistic minority; however, in some cases, the issues that arise - even though for different reasons - may be similar: Price highlights that the "importance of kairotic spaces will be more obvious to a person who - for example - can hear only scraps of a conversation held among a group sitting at a table, or who needs more than a few seconds to process a question asked of her in a classroom discussion" (p. 63). While she is referring to students with mental disability, the results of this study have shown that the issue of "speaking time" or "listening time" arises for some translingual students as well.

Interaction in kairotic spaces poses two main challenges: on the on hand, the need for impromptu reactions causes participants to feel time pressure, and on the other hand, the high stakes of such exchanges - the wish to succeed in class, the wish to be respected 
by one's peers, the fear of being exposed and embarrassed in front of them - causes a social pressure that is felt more strongly by those who constitute a minority in the interaction. Depending on the case, factors of gender, race or culture intersect with linguistic factors and may further raise the stakes for the individual who is in the minority: Liling, as a female Asian engineer, faces the challenge of having to assert herself and reinforce her credibility on many levels. She exposes racism by asking key questions and argues her point by summarizing her knowledge of nuclear power in short, precise statements. Izegbe and Enyo are both instructors, but as black, African women they are at a systemic disadvantage compared to their majority students. While Izegbe embraces her role as an expert on her culture and emphasizes her experience as a researcher to establish authority and credibility, Enyo works her way around the kairotic space, circumventing it by sending emails to students who she feels may refuse to understand her accent. While Samir vividly interacts with Americans, he is sensitive to their tendency to single him out as "different". He wants them to acknowledge that similarities exist apart from difference, and wants to be integrated as part of a group of students working together. Jiang prefers to avoid what he perceives as discomfort and embarrassment at the risk of his grade for participation and silently protests the fact that his teammates exclude him from their conversation.

The five participants navigate the kairotic space in different ways; some flexibly adapt their strategies to address challenges that arise in the moment, improvising with the tools they have, whereas others - particularly the instructors - plan carefully to prepare for kairotic exchanges. What becomes apparent is that all of them do face challenges, whether with regards to time pressure, social pressure, or both. 
If we, as teachers of composition, literacy or even other disciplines, wish to follow the call for a paradigmatic shift towards a pluralistic approach to education, as Cope and Kalantzis have argued almost fifteen years ago, we need to rethink rhetorical agency. The kind of agency participants displayed was highly contextual, pragmatic, creative, spontaneous, reactive rather than proactive, and sometimes cunning. Within the moment, they serve their purpose, but they may not always lead to a sense of empowerment: I am thinking of Liling's experience in particular. Based on my findings, I propose the following three steps as a way for teachers to address translingual students' needs in kairotic spaces:

a. Within our current paradigm of pedagogy, group projects, peer review and other exercises that bring students to interact with each other in kairotic spaces tend to automatically be taken as good teaching practices. However, these forms of interaction need to be planned carefully, keeping in mind that not all students may find it equally comfortable to interact in this manner. Starting a class with an online discussion or online group project rather than proceed to "kairotic" interaction right at the beginning of the semester may be a way to help students ease into the challenges of kairotic exchanges. In a second step, it may be helpful to allow students to choose roles and responsibilities in group work that requires in-person contact: responsibilities may include scheduling meetings, taking "minutes" during meetings, reporting back to the instructor etc. Students who feel discomfort in kairotic interactions may start with a role that includes a higher amount of written interaction (e.g. taking notes during meetings). Later on the semester, responsibilities could rotate among group members. 
b. We need to explicitly address the myth of linguistic homogeneity and help students renegotiate their preconceptions about "standards" and "norms". While a paradigmatic shift towards a translingual understanding of language will take time and efforts on a societal and institutional level, we, as individual scholars and teachers can forward it by better preparing our students: not only do we have an ethical obligation to conduct inclusive teaching practices, taking into account our students diverse and complex identities when we teach. Linguistic diversification is also a reality in our increasingly globalized world. Michigan Tech is only one example of a university where students who have little experience with intercultural encounters "clash" with (linguistic) minorities; sooner or later, however, be it in the work place or any other realm of life, they may find themselves in kairotic spaces with even higher stakes. We can help guide them through the process of understanding the fluidity and emergent nature of language by providing them with appropriate resources and teaching materials: examples of translingual texts - such as postcolonial fiction that plays with practices of "crossing" and "code-meshing"- might serve this purpose well.

c. Finally, I would like to revisit Linda Flower's approach to community literacy projects. She provides a framework for a purposeful, conscious training in rhetorical strategies as a form of empowerment: by learning to speak "with others" through rivalling, minorities and underprivileged students can acquire tools to navigate their ways in kairotic encounters. While participant's strategies are valuable, their dependence on context and spontaneous invention does not necessarily make them reliable strategies. In the long run, complementing 
spontaneous with a active, deliberative strategies may help empower students in such a manner that they can "raise their voices" and be heard. Learning to consciously employ rhetorical strategies of "rivalling" as suggested by Linda Flower - be that as part of a class or in a community project - will help students meet the challenges of time- and social pressure in kairotic exchanges. 


\section{Conclusion}

I came into this project asking how students that constitute a linguistic minority in the classroom navigate kairotic spaces, spaces in which direct interaction is shaped by unequal power relations and high stakes. I found five strategies, four of which are reactive and arise in the moment, while one of them - employed by an instructor, who appeals to academic authority - directly addresses and confronts issues of exclusion and discrimination. In my introduction, I proceeded to ask in how far the rhetorical strategies linguistic minorities employ suffice, and whether they ensure their voices are being heard. Considering the findings of my research, I would say yes - and no.

It is crucial that we value and acknowledge the ways in which students manage to navigate their ways through interactions that are highly challenging, while faced with what seems to be ethnocentric attitudes and a belief that "their" variety of English is less flawed. It is also crucial that, while participants may not necessarily acknowledge their success themselves, some of these strategies are efficient in that they challenge ethnocentric assumptions: I am thinking of Liling's strategy of using "key" statements and questions to expose her group members' possibly racist attitude.

Yet at the same time, Liling reported feeling embarrassed and displayed helplessness and anger in the interview: she was not content with the situation, she did not feel that her strategy was sufficient, and she was left feeling excluded and dissatisfied. That, it seems to me, is what makes the difference in answering whether her strategy "sufficed" - for her, it clearly did not.

How, then, does this exemplary, relatively small-scale study contribute to the overarching question of how we, as teachers and scholars, can transform the classroom 
into a more inclusive space? Clearly, the study is limited not only in scope, but also in perspective: what I saw during observation might differ from what others may have seen, and the stories and emotions students reported on may differ from what others might report. Nevertheless, I believe the examples I provide are indicators of a broader tendency, a tendency that can be felt whenever universities bring together students of different backgrounds, identities, and attitudes: experiences of exclusion, and the pervasiveness of monolingualism, as the literature I am drawing on shows, are not unique to Michigan Tech - they are a phenomenon that concerns universities across the entire United States. What I showed in my study yields questions for further research, questions that need to be addressed urgently and thoroughly if we wish to provide students with an inclusive learning experience: what are strategies that students might feel are more "sufficient" to their needs? What are strategies that might serve to empower them? Can teachers implement them within the classroom, or do we need supporting, out-ofclassroom experiences and projects that serve this purpose? Are community projects, as outlined by Linda Flower, a way of teaching students strategies they can purposefully practice and employ? If so, how can such a project be implemented in the institutional context of the university?

Clearly, the possibilities for research on this topic are endless - what is crucial, however, is that we pay close attention to the struggles of linguistic minorities in the classroom, and that we take into account their specific needs when we attempt to make the classroom and inclusive space for everyone. The framework of "kairotic spaces" has proven to be a helpful tool in describing the challenges that arise out of in-person 
interactions in classrooms, and it may serve in future research to further investigate the topic, even in larger scale or quantitative projects. 


\section{Works Cited}

BERLAK, A. \& Moyenda, S. (2001). Taking it Personally: Racism in the Classroom from Kindergarten to College. Philadelphia (PA):Temple University Press.

CANAGARAJAH, S. (2013). Translingual Practices: Global Englishes and Cosmopolitan Relations. New York (NY): Routledge.

de CERTEAU, M. (1980). The Practice of Everyday Life. Berkeley (CA): University of California Press.

COPE, B. \& Kalantzis, M.(Eds). (2000). Multiliteracies. Literacy Learning and the Design of Social Futures. New York (NY): Routledge.

FLOWER, L. (2008). Community Literacy and the Rhetoric of Public Engagement. Carbondale (IL): Southern Illinois University Press.

FLYNN, E. A., Sotirin, P. \& Brady A. (Eds). (2012). Feminist Rhetorical Resilience. Logan (UT): Utah State University Press.

GLASER, B.G. \& Strauss, A.L. (2012). The Discovery of Grounded Theory. Strategies for Qualitative Research ( $7^{\text {th }}$ ed.). New Brunswick (NJ): Aldine Transaction. 
GRABILL, J. T. (2012). Community-Based Research and the Importance of a Research Stance. In L. Nickoson \& M.P. Sheridan (Eds), Writing Studies Research in Practice. Methods and Methodologies. Carbondale (IL): Southern Illinois University Press.

HARRIS, J. (1995). Negotiating the Contact Zone. Journal of Basic Writing, 14, $27-42$.

HOOKS, b. (1994). Teaching to Transgress. Education as the Practice of Freedom. New York (NY): Routledge.

HORNER, B. \& Trimbur, J. (2002). English Only and U.S. College Composition. College Composition and Communication, 53, 594-630.

HORNER, B., NeCamp, S. \& Donahue, C. (2011). Towards a Multilingual Composition Scholarship: From English Only to a Translingual Norm. College Composition and Communication, 63, 269-300.

JONES ROYSTER, J. (2011). When the First Voice You Hear Is Not Your Own. In V. Villanueva \& Arola, K.A. (Eds). Cross-Talk in Comp Theory. A Reader ( $3^{\text {rd }}$ ed). Urbana (IL): NCTL.

KALANTZIS, M. \& Cope, B. (Eds). (2000). Multiliteracies.Literacy Learning and the Design of Social Futures. New York (NY): Routledge. 
LO BIANCO, J. (2000). Multiliteracies and Multilingualism. In Cope, B. \& Kalantzis, M.(Eds). Multiliteracies. Literacy Learning and the Design of Social Futures. New York (NY): Routledge.

MATSUDA, P.K. (2006). The Myth of Linguistic Homogeneity in U.S. College Composition. College English, 68, 637-651.

MICHIGAN TECHNOLOGICAL UNIVERSITY (MTU). (2014). Enrollment Statistics. Retrieved from http://www.admin.mtu.edu/em/services/erlstat/.

\section{MICHGAN DEPARTMENT OF TECHNOLOGY, MANAGEMENT AND BUDGET}

(DTMB). (2014). Census Statistics and Demographic Data. Retrieved from http://www.michigan.gov/cgi/.

PRATT, M.L. (1991). Arts of the Contact Zone. Profession, 33-40.

PRICE, M. (2011). Mad at School: Rhetorics of Mental Disability and Academic Life. Ann Arbor (MI): University of Michigan Press.

TRACY, S.J. (2013). Qualitative Research Methods. Collecting Evidence, Crafting Analysis, Communicating Impact. Malden (MA): Wiley-Blackwell. 